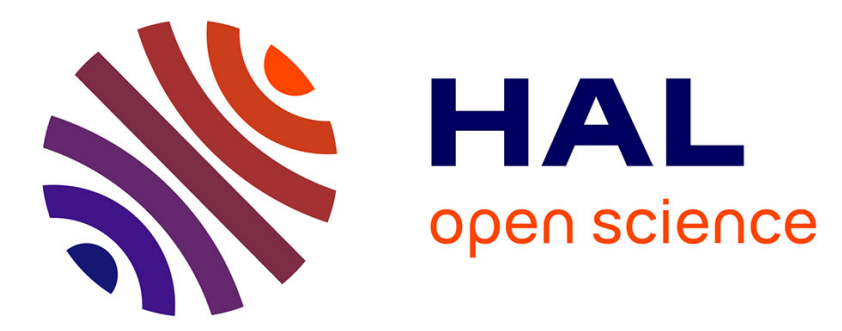

\title{
Why diamond dimensions and electrode geometry are crucial for small photon beam dosimetry
}

Fanny Marsolat, Dominique Tromson, Nicolas Tranchant, Michal Pomorski, C.B Bassinet, C.B Huet, S.C Derreumaux, M.D Chea, K.D Cristina, G.D Boisserie, et al.

\section{To cite this version:}

Fanny Marsolat, Dominique Tromson, Nicolas Tranchant, Michal Pomorski, C.B Bassinet, et al.. Why diamond dimensions and electrode geometry are crucial for small photon beam dosimetry. Journal of Applied Physics, 2015, 118 (23), pp.234507. 10.1063/1.4937994 . cea-01719960

\section{HAL Id: cea-01719960 https://hal-cea.archives-ouvertes.fr/cea-01719960}

Submitted on 15 Oct 2019

HAL is a multi-disciplinary open access archive for the deposit and dissemination of scientific research documents, whether they are published or not. The documents may come from teaching and research institutions in France or abroad, or from public or private research centers.
L'archive ouverte pluridisciplinaire HAL, est destinée au dépôt et à la diffusion de documents scientifiques de niveau recherche, publiés ou non, émanant des établissements d'enseignement et de recherche français ou étrangers, des laboratoires publics ou privés. 


\title{
Why diamond dimensions and electrode geometry are crucial for small photon beam dosimetry
}

F. Marsolat ${ }^{1}$, D. Tromson ${ }^{1}$, N. Tranchant ${ }^{1}$, M. Pomorski ${ }^{1}$, C. Bassinet ${ }^{2}$, C. Huet ${ }^{2}$, S. Derreumaux $^{3}$, M. Chea ${ }^{4}$, K. Cristina ${ }^{4}$, G. Boisserie ${ }^{4}$, I. Buchheit ${ }^{5}$, V. Marchesi ${ }^{5}$, S. GaudaireJosset $^{6}$, A. Lisbona ${ }^{6}$, D. Lazaro ${ }^{7}$, R. Hugon ${ }^{7}$, P. Bergonzo ${ }^{1}$

${ }^{1}$ CEA, LIST, Diamond Sensors Laboratory, 91191 Gif-sur-Yvette, France

${ }^{2}$ IRSN, PRP-HOM/SDE/LDRI, 31 Av. de la Division Leclerc, 92260 Fontenay-aux-Roses, France

${ }^{3}$ IRSN, PRP-HOM/SER/UEM, 31 Av. de la Division Leclerc, 92260 Fontenay-aux-Roses, France

${ }^{4}$ Pitié Salpêtrière Hospital, 47-83 Blvd de l'Hôpital, 75013 Paris, France

${ }^{5}$ Institut de Cancérologie de Lorraine, 6 Av. de Bourgogne, 54500 Vandœuvre-lès-Nancy, France

${ }^{6}$ Institut de Cancérologie de l'Ouest, Blvd Prof. Jacques Monod, 44805 Saint-Herblain, France

${ }^{7}$ CEA, LIST, LM2S, 91191 Gif-sur-Yvette, France

\section{KEY WORDS}

Diode, Ionization chambers, Computational methods, Semiconductor detectors, Radiation therapy, I-V characteristics, Chemical elements, Carbon-based materials, Radiography, Dosimeters

\begin{abstract}
Recent use of very small photon beams (down to $4 \mathrm{~mm}$ ) in stereotactic radiotherapy requires new detectors to accurately determine the delivered dose. Diamond detectors have been presented in the literature as an attractive candidate for this application, due to their small detection volume and the diamond atomic number $(Z=6)$ which is close to water effective atomic number (Zeff 7.42). However, diamond exhibits a density 3.51 times greater than that of water and recent studies using Monte Carlo simulations have demonstrated the drawback of a high-density detector on small beam output factors. The current study focuses on geometrical parameters of diamond detector, namely, the diamond dimensions and the electrode geometry, in order to solve the dosimetric issues still observed in small photon beams with diamond detectors. To give better insights to these open questions, we have used both computational method and experimental analysis. This study highlighted that reducing diamond dimensions is crucial for small beam output factor measurements and to limit the influence of its high density. Furthermore, electrodes covering the whole diamond surface were essential for a dose rate independence of the diamond detector. The optimal dosimeter derived from this work presented small diamond dimensions of approximately $1 \times 1 \times 0.15 \mathrm{~mm}^{3}$, with diamond-like-carbon electrodes covering the whole diamond surface. A dose rate independence of this diamond detector (better than $0.5 \%$ over a wide range of dose rates available on a stereotactic dedicated facility) was obtained due to the electrode geometry. Concerning the output factor measurements, a good agreement (better than 1.1\%) was observed between this carbon material detector and two types of passive dosimeters (LiF microcubes and EBT2 radiochromic films) for all beam sizes except the smallest field of $0.6 \times 0.6 \mathrm{~cm}^{2}$ with a deviation of $2.6 \%$. This new study showed the high performance of this diamond detector in small photon beams, in comparison with various commercially available passive and active dosimeters.
\end{abstract}

\section{INTRODUCTION}

Radiotherapy is one of the most powerful techniques used for cancer treatment. The development of stereotactic treatments in the 1950s has led to an increasing use of small X-ray beams, from 5 to $40 \mathrm{~mm}$ in diameter. A large number of detectors, active and passive, have been manufactured and studied for the accurate dosimetry of such beams: small ionization chambers, plastic scintillators, silicon diodes, diamond detectors, polymer gels, 
thermoluminescent detectors, and radiographic and radiochromic films. However, the dosimetry of small fields is still challenging, the main issue being the determination of the output factor (OF) mainly because of the lack of lateral electronic equilibrium (Das et al., 2008 and Fenwick et al., 2013).

Diamond has been quoted in several papers as being a good candidate for the fabrication of small beam dosimeters (Almaviva et al., 2009; Tromson et al., 2010; Ciancaglioni et al., 2012; Betzel et al., 2012; and Marsolat et al., 2013b). Natural diamonds and, more recently, chemical vapor deposition (CVD)-based diamond detectors have become commercially available from the manufacturer PTW-Freiburg (Germany). Many authors have studied the PTW natural diamond dosimeters (Hoban et al., 1994; Fidanzio et al., 2000; and De Angelis et al., 2002). The non-reproducibility between devices, the high cost, the long delivery times, and particularly their large detection volume are remaining significant drawbacks for these devices.

The performances of synthetic single crystal CVD diamond for X-ray detectors have been presented many times in the literature (Garino et al., 2006; Tranchant et al., 2008; Almaviva et al., 2009; Schirru et al., 2010; Betzel et al., 2012; Marsolat et al., 2013b; Laub and Crilly, 2014; Morales et al., 2014; and Lárraga-Gutiérrez et al., 2015). A high spatial resolution of the dose measurement is made possible using a small diamond sensitive volume. The high density of atoms in its lattice $\left(10^{23}\right.$ atoms $\left.\mathrm{cm}^{-3}\right)$ results in high signal-to-noise ratio even for small detection volumes. Further, the electronic properties of diamond result in fast detector responses. The response stability of most synthetic diamond detectors has often required a pre-irradiation treatment, as reported in the literature, which can vary with the impurity concentrations within the samples (Tromson et al., 2010; Ciancaglioni et al., 2012; and Laub and Crilly, 2014). Nevertheless, a high linearity with dose has been observed in most papers for synthetic diamonds (Tromson et al., 2010; Marsolat et al., 2013b; Laub and Crilly, 2014; Morales et al., 2014; Lárraga-Gutiérrez et al., 2015). The energy independent response of the diamond detector is due to the constant carbon-to-water stopping power ratio over the range of energies used in radiotherapy (Schirru et al., 2010 and Laub and Crilly, 2014).

Furthermore, in the literature, diamond has been described as nearly water-equivalent material because of its atomic number $(Z=6)$ close to that of water (Zeff $\sim 7.42)$. Thus, the diamond detector packaging is considered as a key issue to obtain a water-equivalent dosimeter (Marsolat et al., 2013a) because it can include metal components which reduce the water equivalence further. However, recent Monte Carlo (MC) studies have shown that the dose absorbed by a sensitive detector volume depends with its density when the lateral electronic equilibrium is not reached (Scott et al., 2012; Fenwick et al., 2013; Underwood et al., 2013; Moignier et al., 2014; and Bouchard et al., 2015a; 2015b). These studies have thus highlighted the difficulty of measuring small beam OFs with diamond detectors, and this being related to the diamond density, which is 3.51 times higher than that of water. These results were in good agreement with two recent studies (Ralston et al., 2014 and Underwood et al., 2015) showing the overresponse of the new synthetic PTW micro-diamond detector (type 60019) in small radiation fields. The authors correlated this over-response with the presence of a high-density diamond substrate layer of $400 \mu \mathrm{m}$ thick underneath the device's sensitive volume.

Moreover, several studies addressing the use of synthetic diamond for radiotherapy have also shown a variability in the dependence of the response with the dose rate, evaluated mostly by Fowler equation (Fowler, 1966), with $\Delta$ values ranging from 0.92 to 1.04 (Tranchant et al., 2008; Tromson et al., 2010; Betzel et al., 2012; and Spadaro et al., 2013).

In our previous published study (Marsolat et al., 2013b), a Single Crystal Diamond Dosimeter (SCDDo) based on a commercially available single crystal CVD diamond (Element Six Ltd.) coated with aluminum contacts has been developed specifically for stereotactic radiotherapy. 
The mounted water-equivalent detector has been completely characterized, and this prototype met all the requirements for an adequate radiotherapy dosimeter, that included stability, repeatability, spatial resolution, dose linearity, energy response independence, as well as dose rate independence. This dosimeter has been tested in a clinical environment with small photon beams and has shown the potential for accurate small beam OF measurements in comparison with various commercially available real-time detectors.

All results presented in the literature focused on the detection properties mainly with respect to diamond properties and dosimeter holder properties. Indeed, the high-performance of a diamond dosimeter is partially due to the intrinsic quality of its diamond gem. However, the diamond dimensions and electrodes geometry also play a major role, and this is the focus in the current study. This paper aims to demonstrate that an innovative and optimized geometry is also crucial to obtain the best detection performances obtained in our previously published work (Marsolat et al., 2013b).

We have focused this new study on the main issues of small beam dosimetry observed with diamond detector and reported in the literature, which concern the measurement of small beam OFs and the dose rate dependence of such detectors. Since the holder geometry and the choice of materials surrounding diamond had been optimized from previous studies (Marsolat et al., 2013a), the current work highlighted separately the effects of the diamond dimensions and of the electrode geometry, using both computational method and experimental analysis. Finally, a new low-Z electrode material, namely, diamond-like-carbon (DLC), was investigated with the objective to develop an optimal water-equivalent diamond detector using a pure carbon material device.

\section{MATERIALS AND METHODS}

\section{A. SCDDo fabrication, electrodes configuration, and diamond dimensions}

Element Six electronic grade synthetic single crystal diamonds were used to develop various diamond detector prototypes. For the electrode geometry optimization, the same diamond sample of $2.19 \times 2.19 \times 0.14 \mathrm{~mm}^{3}$ was used, using different electrodes dimensions. $100 \mathrm{~nm}$ thick aluminum electrodes were deposited on both sides of the diamond, using an evaporation system. A first detector (SCDDo-A) was mounted using circular electrodes of $1 \mathrm{~mm}$-diameter. The second one (SCDDo-B) had electrodes that covered the entire diamond surface.

Two sample dimensions were then studied in order to investigate this geometrical impact on small beam dosimetry performances and especially on the OF measurements. These were $4.14 \times 4.13 \times 0.55 \mathrm{~mm}^{3} \quad\left(\right.$ SCDDo-C) and $1.08 \times 1.06 \times 0.16 \mathrm{~mm}^{3}($ SCDDo-D). Aluminum electrodes of millimetric dimensions ensured a small sensitive volume of the detector, as required for small beam dosimetry. Circular electrodes of $1 \mathrm{~mm}$-diameter were deposited on the diamond surface for SCDDo-C, and squared electrodes of about $1 \mathrm{~mm}$ per side covering the whole diamond surface were used to fabricate SCDDo-D for the ease of aluminum evaporation step.

Finally, a new diamond detector (SCDDo-E) was mounted with the small diamond sample of $1.08 \times 1.06 \times 0.16 \mathrm{~mm}^{3}$, with DLC electrodes covering entirely both sides of this diamond. These electrodes were prepared using RF-sputtering of a graphite target in optimized conditions. Table I summarizes the electrodes configurations and surfaces. 
TABLE I. Characteristics of diamond detectors and measurement facilities used in this study.

\begin{tabular}{|c|c|c|c|c|c|}
\hline \multirow[b]{2}{*}{$\begin{array}{l}\text { Diamond } \\
\text { detector }\end{array}$} & \multirow{2}{*}{$\begin{array}{l}\text { Diamond } \\
\text { dimensions } \\
\left(\mathrm{mm}^{3}\right)\end{array}$} & \multirow[b]{2}{*}{$\begin{array}{l}\text { Electrodes } \\
\text { dimensions }\end{array}$} & \multirow[b]{2}{*}{$\begin{array}{l}\text { Electrodes } \\
\text { material }\end{array}$} & \multicolumn{2}{|l|}{ Facility } \\
\hline & & & & $\begin{array}{l}\text { Dose rate } \\
\text { dependence }\end{array}$ & $\begin{array}{l}\text { OF } \\
\text { measurements }\end{array}$ \\
\hline SCDDo-A & $\begin{array}{l}2.19 \times 2.19 \times \\
0.14\end{array}$ & $\begin{array}{l}1 \mathrm{~mm}- \\
\text { diameter }\end{array}$ & $\mathrm{Al}$ & Clinac 2100 & 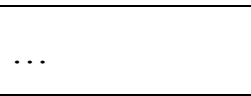 \\
\hline SCDDo-B & $\begin{array}{l}2.19 \times 2.19 \times \\
0.14\end{array}$ & $\begin{array}{l}\text { Covering the } \\
\text { whole surface }\end{array}$ & $\mathrm{Al}$ & Clinac 2100 & $\ldots$ \\
\hline SCDDo-C & $\begin{array}{l}4.14 \times 4.13 \times \\
0.55\end{array}$ & $\begin{array}{l}1 \mathrm{~mm}- \\
\text { diameter }\end{array}$ & $\mathrm{Al}$ & $\ldots$ & $\begin{array}{l}\text { Clinac } 2100 / \\
\text { CyberKnife }\end{array}$ \\
\hline SCDDo-D & $\begin{array}{l}1.08 \times 1.06 \times \\
0.16\end{array}$ & $\begin{array}{l}\text { Covering the } \\
\text { whole surface }\end{array}$ & $\mathrm{Al}$ & $\cdots$ & $\begin{array}{l}\text { Clinac 2100/ } \\
\text { CyberKnife }\end{array}$ \\
\hline SCDDo-E & $\begin{array}{l}1.08 \times 1.06 \times \\
0.16\end{array}$ & $\begin{array}{l}\text { Covering the } \\
\text { whole surface }\end{array}$ & DLC & Novalis & Novalis \\
\hline
\end{tabular}

For each detector, the diamond active volume was then surrounded by low- $Z$ materials as described in our previous work (Marsolat et al., 2013a), namely, aluminum wires of $100 \mu \mathrm{m}$ in diameter were used, all embedded using a conductive graphite glue in Polybenzylmethacrylate (PBnMA) and Polymethylmethacrylate (PMMA) encapsulation. Finally, the triaxial cable was connected to diamond detector at a distance above $3 \mathrm{~cm}$ away from the diamond in order to avoid perturbations of the deposited dose in the diamond, as presented in Figure 1. Contrary to the PTW micro-diamond detector, the diamond chip was oriented with its faces parallel to the detector axis.

FIG. 1.(a) Sketch of SCDDo with near water-equivalent surrounding materials. (b) X-rays radiography of the device.
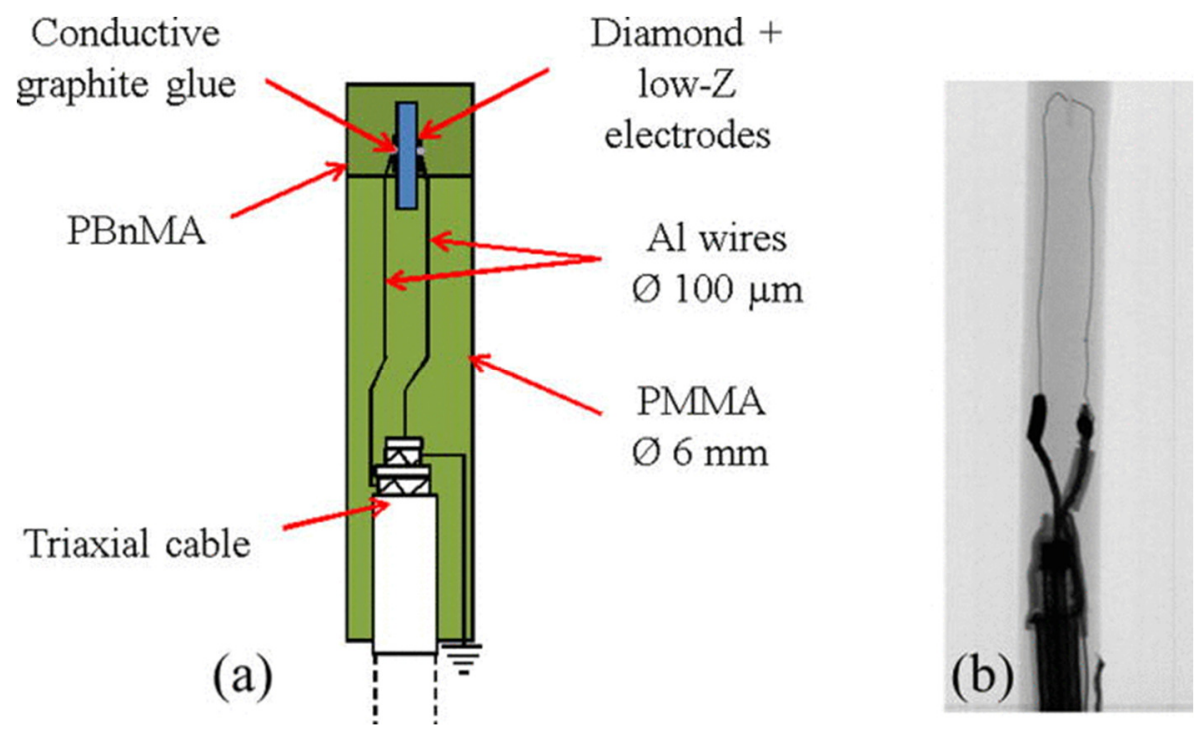


\section{B. Commercially available active and passive detectors}

In this study, SCDDo was compared with different types of commercially available detectors dedicated to dose measurements in small beams. Two types of passive detectors were used, namely, the small thermoluminescent microcubes of $\mathrm{LiF}: \mathrm{Mg}, \mathrm{Ti} \quad\left(1 \times 1 \times 1 \mathrm{~mm}^{3}\right)$ commercialized by Harshaw (Bassinet et al., 2010) and the EBT2 radiochromic films from ISP (Huet et al., 2012). The protocol for $\mu \mathrm{LiF}$ and EBT2 dosimetry was described by Bassinet et al. (2013). A region of interest (ROI) of $2.5 \mathrm{~mm}$ in diameter was used for estimating the OFs using EBT2 films for the largest field sizes of this study. The ROI sizes leading to a negligible volume averaging effect in small beams were determined with MC simulations and are reported in Table II.

TABLE II. ROI sizes for estimating the film OFs with a negligible volume averaging effect.

\begin{tabular}{|c|c|}
\hline Field width: side length or diameter $\mathbf{( m m})$ & ROI diameter $(\mathbf{m m})$ \\
\hline 5 & 0.33 \\
\hline 6 & 0.4 \\
\hline 7.5 & 0.5 \\
\hline 10 & 0.67 \\
\hline 12 & 0.83 \\
\hline
\end{tabular}

EBT2 films have been used as reference detectors in small beam dosimetry by Ralston et al. (2012) to validate the measurements performed with an air core fibre optic scintillation dosimeter. Bassinet et al. (2013) and Moignier et al. (2014) have shown that EBT2 films and $\mu \mathrm{LiF}$ TLD could be used together without correction factors as verification dosimeters for the OF measurements in small beams. Pantelis et al. (2012) have also used radiochromic films in addition to TLD, alanine, and polymer gels as reference dosimeters in small beams. In this study, we used together $\mu \mathrm{LiF}$ and EBT2 films without correction factors as proposed by Bassinet et al. (2013) and Moignier et al. (2014).

The unshielded 60017 diode (PTW-Freiburg, Germany) is a p-type silicon diode operating at $0 \mathrm{~V}$, with a disk-shaped sensitive volume perpendicular to the detector axis. Its detection volume is $0.6 \mathrm{~mm}$ in diameter and $30 \mu \mathrm{m}$ in thickness. A good performance of this new unshielded diode and its previous model (PTW 60012) has been observed by many authors (Griessbach et al., 2005; Scherf et al., 2009; Pantelis et al., 2010; Pantelis et al., 2012; and Dzierma et al. 2012) in small beam measurements, compared with shielded diodes. The copper shielded n-type EDGE diode (Sun Nuclear Corporation, Florida, USA), polarized at $0 \mathrm{~V}$, with a surface area of $0.64 \mathrm{~mm}^{2}$ and thickness of $30 \mu \mathrm{m}$ has been investigated as well. The PTW 31014 PinPoint ionization chamber is a miniaturized ionization chamber commercially available for small beam and is known as a good reference detector for beam sizes ranging from $3 \times 3 \mathrm{~cm}^{2}$ to $10 \times 10 \mathrm{~cm}^{2}$ (Martens et al., 2000; Laub and Wong, 2003; and Scott et al., 2008). It operates at the nominal voltage of $\pm 400 \mathrm{~V}$ and has a volume of $15 \mathrm{~mm}^{3}(2 \mathrm{~mm}$ diameter by $5 \mathrm{~mm}$ length). The measurements with the diodes and the ionization chamber have been previously published (Bassinet et al., 2013) and were included in this new study for comparative purposes only. 


\section{Radiation beam and experimental set-up}

Current-voltage (I-V) characteristics of diamond devices were first examined in order to determine the optimal operating voltages for maximum charge collection. The current measured under radiation versus bias voltage or versus electric field applied to the detector was recorded for electric field intensities up to approximately $0.6 \mathrm{~V} \mu \mathrm{m}^{-1}$. These measurements were performed using a remotely controlled Keithley $6517 \mathrm{~A}$ electrometer in an experimental low energy X-ray tube $(50 \mathrm{kV})$.

Clinical environment measurements were then performed with diamond detectors for three types of facilities in France: a CyberKnife system (Institut de Cancérologie de Lorraine), an adaptive Varian Clinac 2100 medical linear accelerator equipped with an additional micro multileaf collimator system mMLC m3 from BrainLab (La Pitié Salpêtrière Hospital), and a Varian/BrainLab Novalis system (Institut de Cancérologie de l'Ouest). The CyberKnife model operates at 600 Monitor-Units $\mathrm{min}^{-1}\left(\mathrm{MU} \mathrm{min} \mathrm{m}^{-1}\right)$ and uses circular collimators. The dedicated medical linear accelerator Novalis is based on a Varian Clinac but integrates the BrainLab mMLC m3 collimator for stereotactic treatment. The dose rate varies from $80 \mathrm{MU} \mathrm{min}^{-1}$ to 400 MU min ${ }^{-1}$ for the Clinac 2100 and from $160 \mathrm{MU} \mathrm{min}^{-1}$ to $800 \mathrm{MU} \mathrm{min}^{-1}$ for the Novalis system.

Measurements were performed in a water phantom at a source-surface distance (SSD) of $78.5 \mathrm{~cm}$ for the CyberKnife and $100 \mathrm{~cm}$ for both Varian accelerators as recommended by vendors. Each diamond detector was positioned in the water tank with its cable parallel to the beam axis and the smallest dimension of the diamond detection volume (its thickness) in crossline direction. In this cable orientation, similar to that recommended by the manufacturer for the PTW 60019 diamond detector, the small thickness of the diamond chip was faced to the beam. Consequently, the volume averaging effect was reduced in comparison with the commercial device with its wider side facing the beam. All measurements were performed with a $6 \mathrm{MV}$ photon beam at a depth of $1.5 \mathrm{~cm}$ for the CyberKnife and $10 \mathrm{~cm}$ for both Varian accelerators as illustrated in Figure 2.

FIG. 2.Reference conditions for CCE measurements, OF determination, and dose rate dependence study for both Varian accelerators (the Clinac 2100 equipped with mMLC and the Novalis) (a) and the CyberKnife system (b).

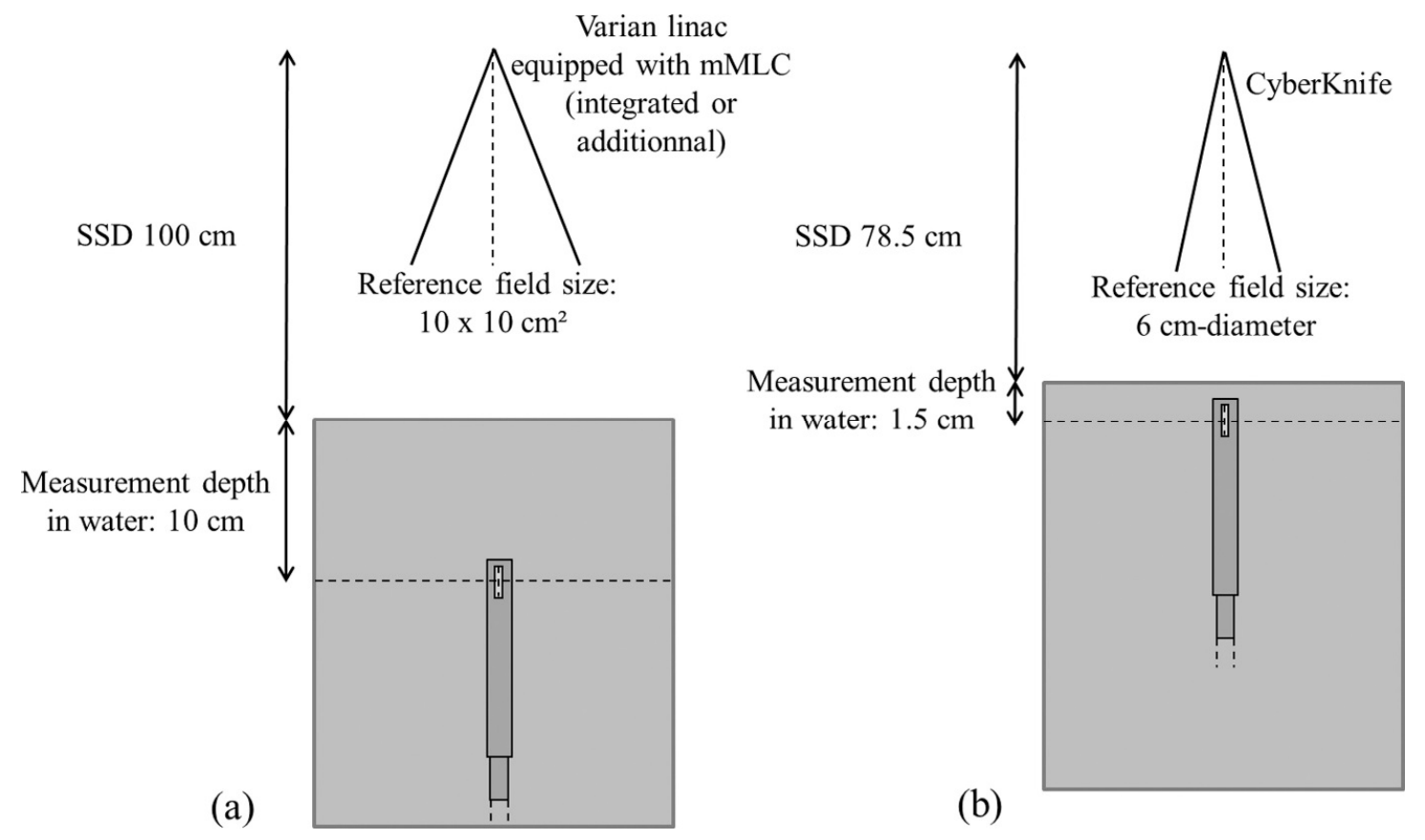


Precise positioning of the detector reference point on the beam axis was performed by acquiring lateral dose profiles in both directions (cross-line and in-line), for the smallest field size available on each radiotherapy facility. The detectors were placed at maximum dose value in each direction. After detector positioning, SCDDo was connected to the Keithley $6517 \mathrm{~A}$ electrometer for the collection charge efficiency (CCE) measurements and to a PTW UNIDOS electrometer for $\mathrm{OF}$ measurements or for the dose rate dependence study.

CCE is defined as the ratio of the measured current $I_{R}$ and the theoretical current value $I_{P}$ described by the following equation (Hoban et al., 1994 and Schirru et al., 2010):

$I_{P}=\frac{\dot{D} \rho_{\text {diam }} e V}{\omega}$

With $\dot{D}$ the dose rate in diamond, $\rho_{\text {diam }}$ the diamond density $\left(\rho_{\text {diam }}=3.51\right)$, $e$ the elementary charge, $V$ the sensitive volume, and $\omega$ the energy required to create an electron-hole pair in diamond $(\omega=13 \mathrm{eV})$. The maximum CCE was investigated for the detector SCDDo-B on the Clinac 2100 facility, by measuring $I_{R}$ with a polarization voltage giving the maximum current value according to its $\mathrm{I}-\mathrm{V}$ characteristic. In the expression of $I_{P}, \dot{\mathrm{D}}$ corresponds to the dose rate in diamond, which is equal to the dose rate in water measured with a calibrated PTW 31003 ionization chamber divided by a factor of 1.15. This factor provided a good approximation of the ratio dose to water to dose to diamond when the electronic equilibrium is reached, according to the study of Fenwick et al. (2013). The methodology described in IAEA report 398 was applied to determine the absorbed dose to water.

The dose rate dependence of the detector response was then investigated on the Clinac 2100, as a function of the electrode geometry, namely, for SCDDo-A and SCDDo-B. This study was performed using a $10 \times 10 \mathrm{~cm}^{2}$ field, and the pulse repetition frequency was varied over the whole range of dose rates available on this facility, namely, from $80 \mathrm{MU} \mathrm{min}^{-1}$ to $400 \mathrm{MU} \mathrm{min}^{-1}$. Charge measurements were performed by irradiating each detector at each pulse repetition frequency with a constant dose of $200 \mathrm{MU}$. For good statistics, five readings of the charge were taken at each dose rate and the average of SCDDo reading was calculated. The dose rate dependence study was then investigated for DLC-electrodes (SCDDo-E) on the Novalis system, in the same measurement conditions, but for dose rates ranging from $160 \mathrm{MU} \mathrm{min}{ }^{-1}$ to $800 \mathrm{MU}$ $\min ^{-1}$.

Small beam OF measurements were then investigated as a function of diamond dimensions, with SCDDo-C and SCDDo-D, on both CyberKnife system and Clinac 2100 accelerator. These measurements were performed using a dose rate of $600 \mathrm{MU} \mathrm{min}^{-1}$ for the CyberKnife and 400 MU $\mathrm{min}^{-1}$ for the Clinac 2100 facility. OFs were measured for beam sizes ranging from $0.5 \mathrm{~cm}$ to $6 \mathrm{~cm}$ in diameter with the CyberKnife, and from $0.6 \times 0.6 \mathrm{~cm}^{2}$ to $10 \times 10 \mathrm{~cm}^{2}$ for the Clinac 2100 , the larger field of each facility being chosen as the reference field. As recommended by BrainLab instructions (BrainLab Physics 2008) a systematic few millimeters withdrawal of the jaws outside the field defined by the leaves of the mMLC enabled uncertainties arising from the jaw's aperture and centering to be reduced (Table III). Five consecutive measurements were taken for each beam size as well as for each diamond dosimeter, and the mean reading was then calculated. These OF values were then compared with those measured with the passive detectors ( $\mu \mathrm{LiF}$ and EBT2 films). 
TABLE III. Field sizes with mMLC.

\begin{tabular}{|l|l|}
\hline $\mathbf{m M L C}$ size $\left.\mathbf{( m m}^{2}\right)$ & Jaws size $\left.\mathbf{( m m}^{2}\right)$ \\
\hline $6 \times 6$ & $8 \times 8$ \\
\hline $12 \times 12$ & $14 \times 14$ \\
\hline $18 \times 18$ & $20 \times 20$ \\
\hline $24 \times 24$ & $44 \times 44$ \\
\hline $30 \times 30$ & $44 \times 44$ \\
\hline $36 \times 36$ & $44 \times 44$ \\
\hline $42 \times 42$ & $44 \times 44$ \\
\hline $60 \times 60$ & $60 \times 60$ \\
\hline $80 \times 80$ & $80 \times 80$ \\
\hline $100 \times 100$ & $98 \times 98$ \\
\hline
\end{tabular}

Finally, OFs were measured with SCDDo-E on the Novalis accelerator, in the same conditions as those used for the Clinac 2100 facility, but at a dose rate of $480 \mathrm{MU} \mathrm{min}{ }^{-1}$ commonly used for treatment. These OF values were then compared with values obtained with various dosimeters, active and passive, as described previously (Bassinet et al., 2013). The OFs were then renormalized to a smaller field of $4.2 \times 4.2 \mathrm{~cm}^{2}$ in order to avoid biasing the results with the unshielded silicon diodes, which are known to over-respond in larger fields (Gagnon et al., 2012).

Table I summarizes the radiotherapy facilities for which the dose rate dependence was studied and the OFs were measured with each detector.

\section{Monte Carlo simulations}

MC simulations were performed using the PENELOPE code (2006 parallelized version) developed by Salvat et al. (2006). In order to optimize the diamond dimensions for small photon beam dosimetry, energy spectra representative of such beams were needed. These energy spectra were obtained by using a MC model of a Saturne 43 linac previously validated against experiments for a $10 \times 10 \mathrm{~cm}^{2}$ field size (Mazurier et al., 1999) and already used in a previous work (Marsolat et al., 2013a). The Saturne 43 medical linear accelerator head geometry was modeled using PENGEOM (PENELOPE geometry code). The transport of radiation was simulated through the accelerator head. Different Phase Space Files (PSF) were then recorded at $90 \mathrm{~cm}$ from the source, in air, for a $6 \mathrm{MV}$ photon beam and field sizes varying from $0.5 \times 0.5 \mathrm{~cm}^{2}$ to $10 \times 10 \mathrm{~cm}^{2}$. These files contained data related to every particle crossing a surface of $30 \times 30 \mathrm{~cm}^{2}$, orthogonal to the beam axis: kind of particles, energy, position, and direction. These PSF were then used to study the influence of diamond dimensions on OF. The energy photon spectra of the PSF obtained for $0.5 \times 0.5 \mathrm{~cm}^{2}, 2 \times 2 \mathrm{~cm}^{2}, 5 \times 5 \mathrm{~cm}^{2}$, and $10 \times 10 \mathrm{~cm}^{2}$ fields were compared (Figure 3), and the main characteristic expected for a small beam was verified: the mean energy of photons increases for smaller beam size due to the lower quantity of scattered photons in the linear accelerator head (Table IV).

FIG. 3.Energy spectra of photons calculated in air, at $90 \mathrm{~cm}$ from the target of a Saturne 43 linac, for $6 \mathrm{MV}$ photon beams and various field sizes. Spectra resolution: $50 \mathrm{keV}$. Spectra are normalized to the total number of photons 


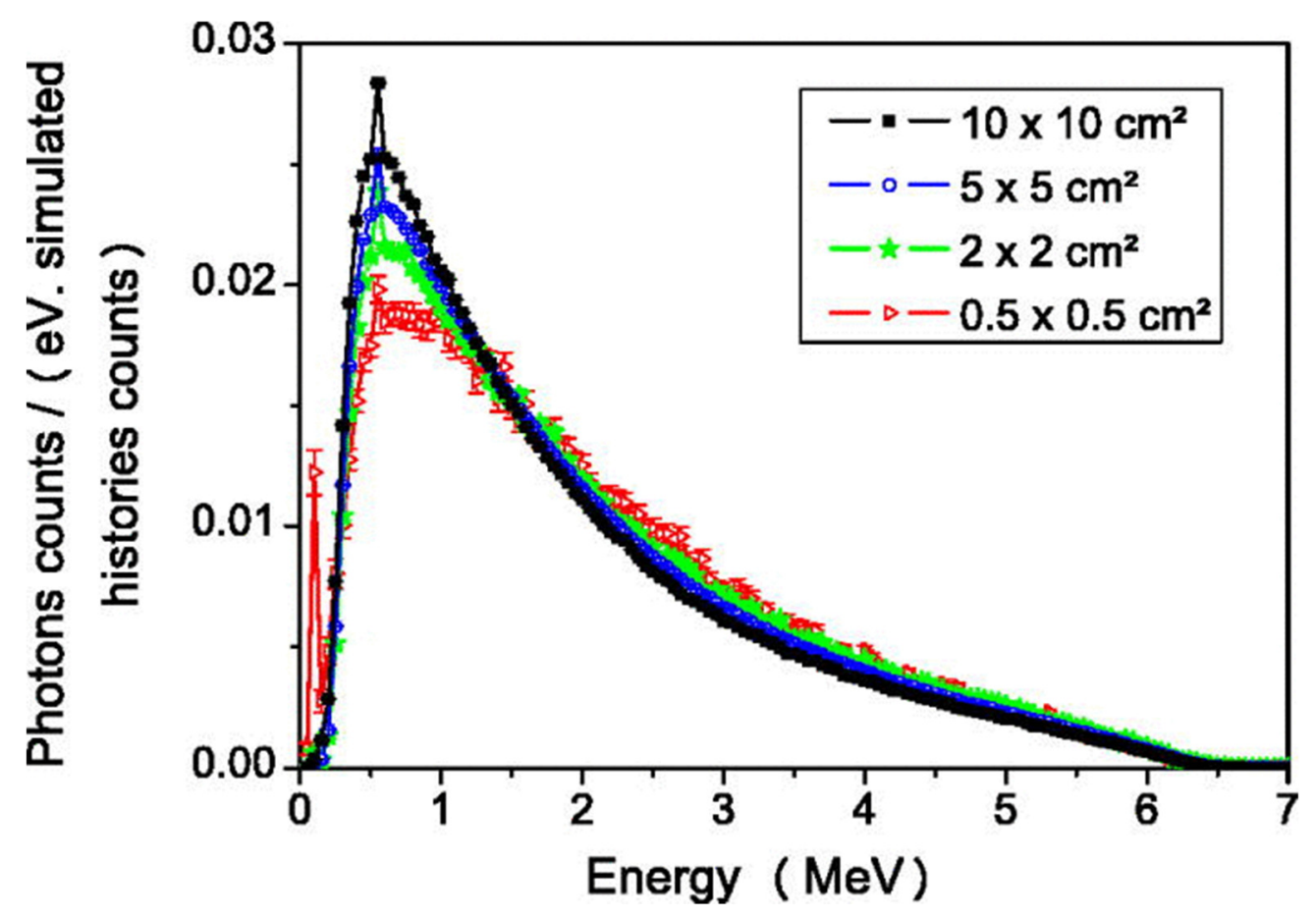

TABLE IV. Mean energy of photon beams calculated in air, at $90 \mathrm{~cm}$ from the target of a Saturne 43 linac, for 6 MV photon beams and various field sizes.

\begin{tabular}{|c|c|}
\hline Field size $\left(\mathbf{c m}^{\mathbf{2}}\right)$ & Mean energy of photon beams $\mathbf{( M e V )}$ \\
\hline $0.5 \times 0.5$ & 2.00 \\
\hline $2 \times 2$ & 1.98 \\
\hline $5 \times 5$ & 1.91 \\
\hline $10 \times 10$ & 1.82 \\
\hline
\end{tabular}

The surrounding materials have already been studied (Marsolat et al., 2013a) and were not taken into account in the current simulation work in order to focus on the optimization of the singlecrystal sample dimensions. Diamond was modeled as carbon material, with a density of 3.51, mean excitation energy of $87.6 \mathrm{eV}$ (Gorka et al., 2006), lateral dimensions varying from $1 \times 1 \mathrm{~mm}^{2}$ to $4 \times 4 \mathrm{~mm}^{2}$, and thickness ranging from $150 \mu \mathrm{m}$ to $550 \mu \mathrm{m}$, which included the dimensions of SCDDo-C and SCDDo-D presented previously. For this MC simulation work, the sensitive volume in which $O F$ was calculated was defined as the volume of diamond situated between both electrodes. For diamond with lateral dimensions of $1 \times 1 \mathrm{~mm}^{2}$, squared electrodes covering the entire diamond surface were considered, and in this case the active volume corresponded to the diamond volume. For diamond with lateral dimensions above $1 \times 1 \mathrm{~mm}^{2}$, circular electrodes of $1 \mathrm{~mm}$-diameter allowed to define the sensitive volume as a small cylinder of $1 \mathrm{~mm}$-diameter and with a height equal to the diamond thickness, positioned at the center of the sample. Consequently, for all diamond dimensions, small active volumes were observed, as required for small beam dosimetry. In this study, the minimum sensitive volume exhibits dimensions of $1 \times 1 \times 0.15 \mathrm{~mm}^{3}$, in order to ensure a sufficiently high signal to noise ratio in photon beams, with still a good spatial resolution in all directions.

The sensitive volume of each diamond detector was centered on the beam axis, at $5 \mathrm{~cm}$ depth in a $20 \times 20 \times 20 \mathrm{~cm}^{3}$ water tank with an SSD of $100 \mathrm{~cm}$. And the dose deposited in the sensitive 
volume of $1 \mathrm{~mm}$ dimensions (diameter or side) was calculated for each beam size, in order to calculate OF with $10 \times 10 \mathrm{~cm}^{2}$ beam as reference field. These OF values were then compared with "reference" water OFs, calculated in a very small voxel of water equivalent to the smallest diamond volume of this study $\left(1 \times 1 \times 0.15 \mathrm{~mm}^{3}\right)$. The diamond and the reference water voxel were oriented vertically with their smallest dimension (their thickness) in a cross-line direction, facing the beam, as for the experimental OF determination.

To achieve a relatively low uncertainty in the small sensitive volume of SCDDo $(<2 \%)$, a high number of simulated particles and hence long calculation times were required. The values of some PENELOPE user-defined parameters were carefully chosen in order to speed up simulations and to preserve a high accuracy. EABS is the cutoff energy defined for each kind of particles: electrons, positrons, and photons. The transport of a particle is discontinued when its energy reaches the EABS value: the particle is then assumed to be absorbed in the medium and its energy is locally deposited. Four other parameters are specific to electron and positron transport, namely, $\mathrm{C} 1, \mathrm{C} 2, \mathrm{WCC}$, and $\mathrm{WCR}$. $\mathrm{C} 1$ and $\mathrm{C} 2$ define the average angular deflection and the maximum average fractional energy loss between consecutive hard elastic events, respectively. $\mathrm{C} 1$ and $\mathrm{C} 2$ can take values from 0 to 0.2 . If both parameters are set to zero, the simulation is performed in a very detailed way but takes a long time. The simulation is speeded up using larger values of $\mathrm{C} 1$ and $\mathrm{C} 2$, at the expense of accuracy. WCC and WCR are the cutoff energy loss for hard inelastic collisions and hard bremsstrahlung emission, respectively. To achieve a good energy resolution, WCC and WCR should have small values. These parameters were selected in order to keep a high accuracy in diamond or in the "reference" voxel of water, but it implies long calculation time: EABS was set to $0.5 \mathrm{keV}$ for all kind of particles, $\mathrm{C} 1$ and $\mathrm{C} 2$ were set to 0.01 , and WCR and $\mathrm{WCC}$ were equal to $0.05 \mathrm{eV}$. To speed up simulations, these parameter values were successively increased in regions surrounding the volume of interest, where lower accuracy was needed, as described by Gorka et al. (2006) and as presented in our previous study (Marsolat et al., 2013a). These parameters are reported in Table V.

TABLE V. PENELOPE parameters selected to study the influence of diamond dimensions on the absorbed dose to diamond. These parameters determine the accuracy and the speed of the simulation.

\begin{tabular}{|c|c|c|c|c|c|}
\hline \multirow[b]{2}{*}{ Region } & \multicolumn{2}{|c|}{ EABS (keV) } & \multirow[b]{2}{*}{$\mathrm{C} 1, \mathrm{C} 2$} & \multirow[b]{2}{*}{ WCC (keV) } & \multirow[b]{2}{*}{ WCR (keV) } \\
\hline & $\begin{array}{l}\text { Electrons, } \\
\text { positrons }\end{array}$ & Photons & & & \\
\hline $\begin{array}{l}\text { 1: Diamond or } \\
\text { "reference" voxel } \\
\text { of water }\end{array}$ & 0.5 & 0.5 & 0.01 & $0.05 \times 10^{-3}$ & $0.05 \times 10^{-3}$ \\
\hline $\begin{array}{lr}2: & \text { Region } \\
1+0.1 \mathrm{~cm} & \text { of } \\
\text { water } & \end{array}$ & 1 & 1 & 0.05 & 1 & 1 \\
\hline $\begin{array}{l}3: \quad \text { Region } \\
2+1 \mathrm{~cm} \text { of water }\end{array}$ & 100 & 5 & 0.1 & 10 & 10 \\
\hline $\begin{array}{ll}\text { 4: } & \text { Remaining } \\
\text { water } & \end{array}$ & 500 & 5 & 0.2 & 10 & 10 \\
\hline
\end{tabular}




\section{E. Electric field computation in diamond detector using Quickfield software}

To evaluate the impact of the electrode geometry on the dose measurement, especially on the $\mathrm{I}-\mathrm{V}$ characteristics under X-rays and on the dose rate dependence, the electric field lines and electric field intensity within the diamond detector were calculated using Quickfield (Tera Analysis Ltd., Denmark). This software is focusing in solving partial differential equations in 2D and 3D using finite element method. The user defines a particular geometry, then generates a mesh within the geometry, selects materials for the objects, determines the boundary conditions (Neumann or Dirichlet), and finally applies the appropriate physics to the system. The web of created points within the geometry is then used to calculate the physical results. In this work, diamond detector was modelled using the electrostatics solving equation, for which the physics is governed by charge conservation and conventional electrostatics laws.

The electric field in the diamond was simulated numerically in a 2D plane, going through the middle of the diamond sample. We assumed here that the materials surrounding diamond (PBnMA and PMMA) were fully insulating. The lower electrode was connected to ground and a high voltage applied to the top one, to obtain a uniform electric field of $1 \mathrm{~V}_{\mu \mathrm{m}^{-1}}$ in the center of the diamond. The volume situated between both electrodes is called $V_{e}$ in this work. These simulations were performed for the following geometrical objects:

- a diamond sample of $1 \times 1 \times 0.14 \mathrm{~mm}^{3}$ with electrodes covering the whole surface, similar to SCDDo-D with $+140 \mathrm{~V}$ bias

- a diamond sample of $2 \times 2 \times 0.14 \mathrm{~mm}^{3}$ with electrodes covering the whole surface, similar to SCDDo-B with $+140 \mathrm{~V}$ bias.

- a diamond sample of $2 \times 2 \times 0.14 \mathrm{~mm}^{3}$ with electrodes of $1 \mathrm{~mm}$ diameter, similar to SCDDo-A with $+140 \mathrm{~V}$ bias.

\section{RESULTS AND DISCUSSION}

\section{A. Impact of electrode geometry on I-V curves and dose rate dependence}

\section{I-V curves}

I-V characteristics measured for SCDDo-A and SCDDo-B under low energy X-rays are displayed in Figure 4 for both electrode geometries deposited on the same diamond sample: electrodes of $1 \mathrm{~mm}$ diameter (so-called partial electrode) and electrodes covering the whole diamond surface (so-called covering electrode). These I-V curves are symmetrical, but for the partial electrodes, the measured current continues to increase with the applied voltage over the whole range of bias voltage tested in this work (from $-100 \mathrm{~V}$ to $+100 \mathrm{~V}$ ), as opposed to the covering electrodes for which the current remains constant $(4.9 \mathrm{nA})$ for voltage higher than $20 \mathrm{~V}$. 
FIG. 4.I-V curve characteristics measured for SCDDo-A (1 mm-diameter electrodes) and SCDDo-B (covering electrodes) under X-rays produced by an experimental tube $(50 \mathrm{kV})$.

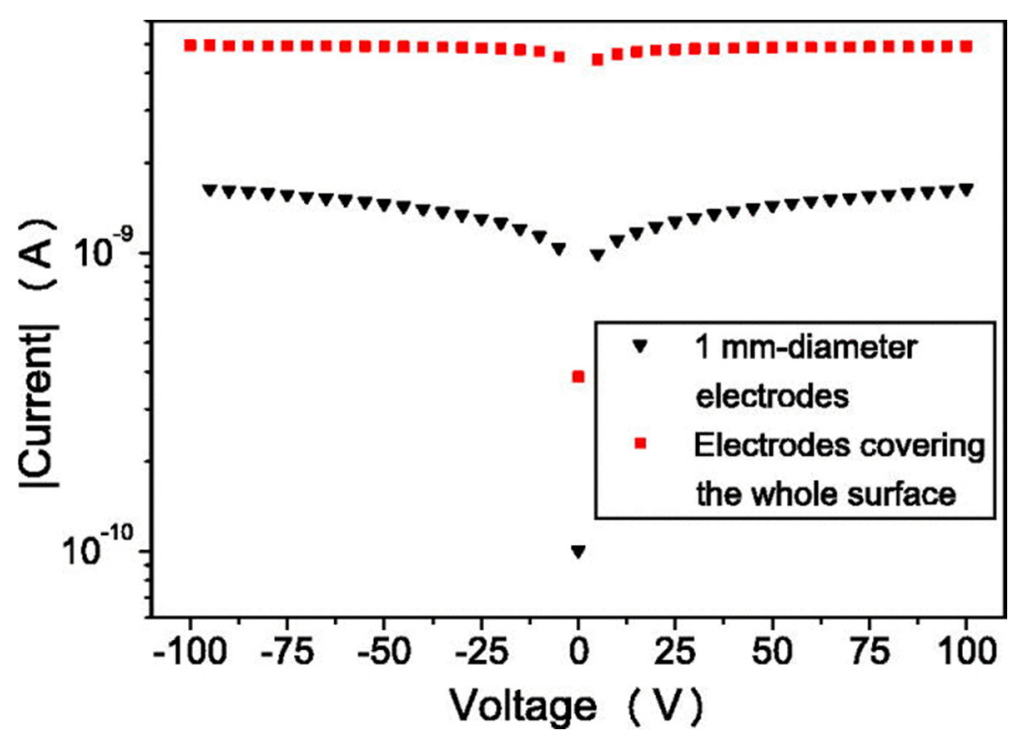

The saturation current measured with SCDDo-B was then compared with the theoretical current value $I_{P}$ described by Equation (1) in order to evaluate the CCE. This measurement was performed on the Clinac 2100 facility for which the absorbed dose to water was accurately determined: $\dot{\mathrm{D}} \omega=2.66 \mathrm{~Gy} \mathrm{~min}^{-1}$. In these conditions, at a polarization voltage of $+50 \mathrm{~V}$, a saturation current $I_{R}$ of $6.5 \mathrm{nA}$ was measured. Assuming a SCDDo sensitive volume $V=0.67 \mathrm{~mm}^{3}$, a CCE of $93 \% \pm 8 \%$ was obtained. This result allowed to confirm the maximum $\mathrm{CCE}$ at bias voltages above $20 \mathrm{~V}$, due to the high quality of diamond material and the geometry of electrical contacts covering the whole surface of diamond.

Electric field lines and strengths within the diamond detector, evaluated using Quickfield software, are displayed in Figure 5 for different diamonds and electrode geometries. This figure demonstrates that the electric field lines are perpendicular to the electrodes within the volume $V_{e}$. Assuming insulating surrounding materials, the detection volume is equal to the volume $V_{e}$ for both configurations $a$ and $b$ with covering electrodes. This figure shows also the homogeneity of the electric field intensity within diamond for these two configurations. 
FIG. 5.Electric field lines and strength calculated in a 2D-plane through the diamond detector, using Quickfield software for various diamond dimensions and electrodes geometries. (a) Diamond of $1 \times 1 \times 0.14 \mathrm{~mm}^{3}$ with covering electrodes. (b) Diamond of $2 \times 2 \times 0.14 \mathrm{~mm}^{3}$ with covering electrodes. (c) Diamond of $2 \times 2 \times 0.14 \mathrm{~mm}^{3}$ with partial electrodes of $1 \mathrm{~mm}$-diameter.

(a)

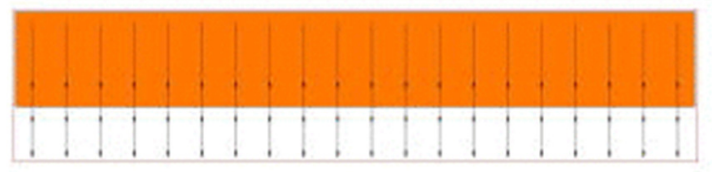

Strength $E$

$10^{6} \mathrm{~V} / \mu \mathrm{m}$

1.10

0.99

0.88

0.77

0.66

0.55

(b)

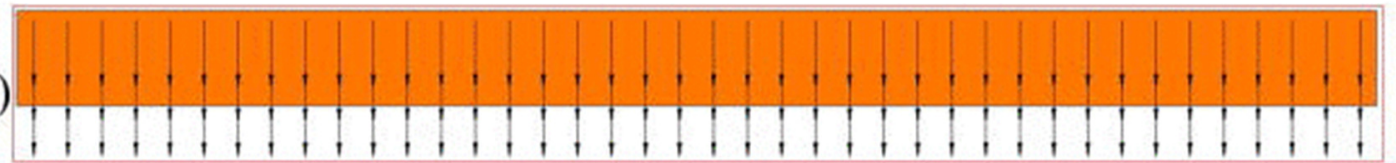

0.44

0.33

0.22

(c)

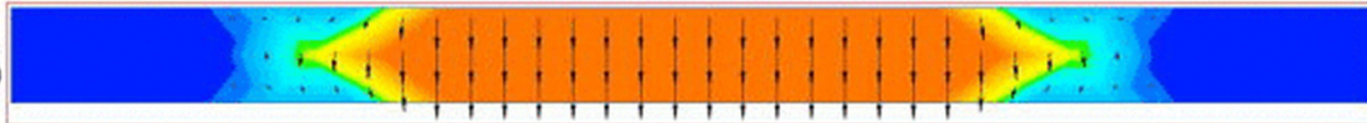

For the other configuration $(c)$ with partial electrodes, the electric field lines extend outside $V_{e}$, indicating that the sensitive volume is larger than $V_{e}$. Figure 5 reveals that a non-zero electric field value exists outside $V_{e}$ when the electrodes are kept smaller than the diamond. This implies that a part of charges created in diamond outside $V_{e}$ can be collected and thus participates to the signal. In this region, when the bias voltage increases, the electric field intensity in diamond increases and consequently the quantity of collected charges increases as well. However, for a $100 \mathrm{~V}$ bias voltage which is the maximum voltage tested in this work, the electric field is still too weak to obtain a $100 \% \mathrm{CCE}$ in the region outside $V_{e}$. This explains the increasing current on the I-V curves for diamond presenting partially covering electrodes, whereas a close to ideal $\mathrm{I}-\mathrm{V}$ response that displays the $100 \% \mathrm{CCE}$ is observed when the electrodes cover the entire diamond surface.

\section{Dose-rate dependence}

The influence of electrodes geometry was studied for SCDDo-A and SCDDo-B presented previously. Dose rate curves were measured at $+50 \mathrm{~V}$ corresponding to a maximum CCE of about $100 \%$ for SCDDo-B with electrodes covering the whole surface, as shown previously. Figure 6 shows the dose rate dependence of both detectors in a $6 \mathrm{MV}$ photon beam. The percentage deviation of the measured charge with respect to the one measured for the maximum

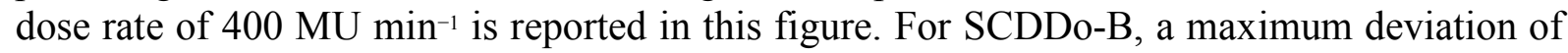
$1.2 \%$ was found in the investigated dose rate, indicating negligible dose rate dependence, as opposed to SCDDo-A that exhibited a maximum deviation of $6.1 \%$. 
FIG. 6.Dose rate dependence of SCDDo-A (1 mm-diameter electrodes) and SCDDo-B (covering electrodes) response in a $10 \times 10 \mathrm{~cm}^{2}$ field. Percentage deviation of the measured charge with respect to the one measured at $400 \mathrm{MU} \mathrm{min}^{-1}$ is reported as a function of the dose rate.

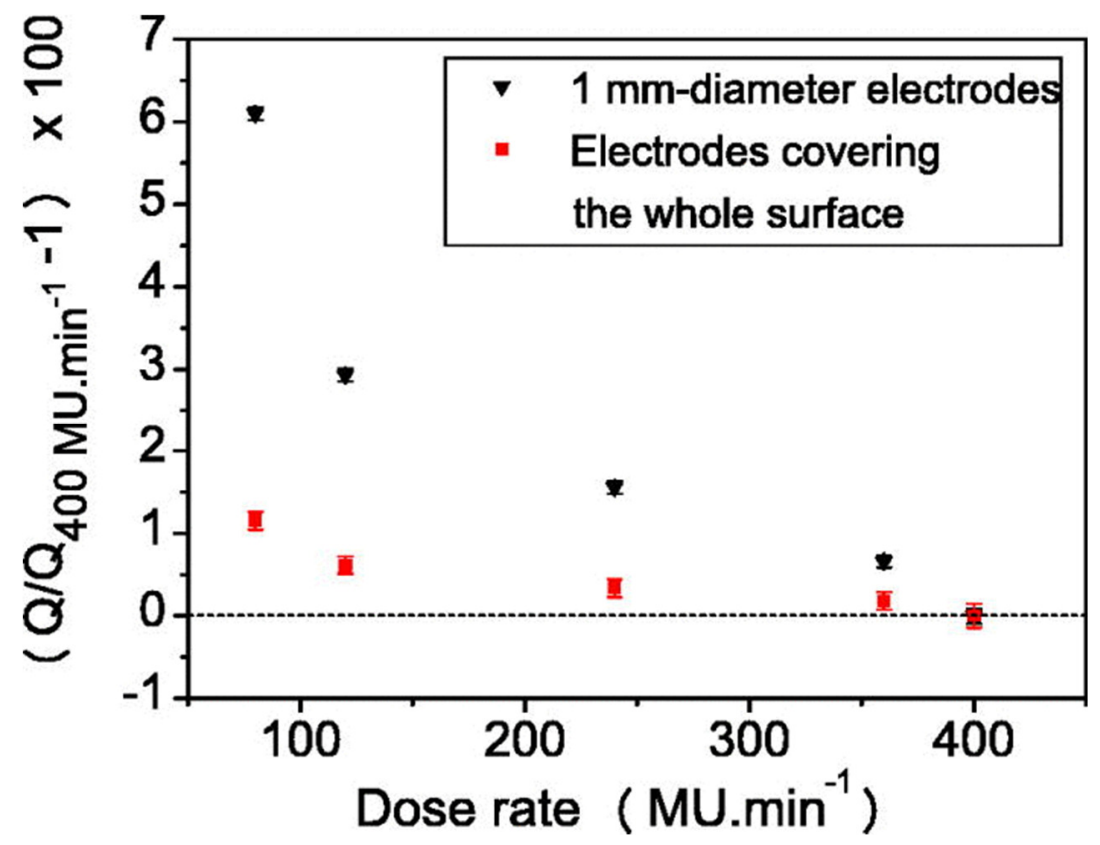

In fact, for partial electrodes, Figure 5 displays that there remains a very low electric field outside the electrodes, where carriers could potentially be collected. However, and as proposed by Bergonzo et al. (2007), the signal generated in diamond results in carrier migration, and some may partially be weakly trapped by shallow defects and released at room temperatures. Due to the global carrier displacement in the diamond, this weak trapping results in the progressive build-up of a weak internal electric field $\mathbf{E}_{\mathbf{i}}$ in the opposite direction to that of the applied electric field $\mathbf{E}$ and that increases with the quantity of created carriers and hence with the dose rate. The resulting total electric field $\mathbf{E}_{\mathbf{t}}$ in diamond is consequently reduced by $\mathbf{E}_{\mathrm{i}}$ from the applied field which is weak outside the contacts, and the higher the dose rate, the worse the effect. Consequently, in the case of partial electrodes, $\mathbf{E}_{\mathbf{i}}$ appears as non-negligible with respect to the low field outside the electrodes, and therefore significantly lowers the device response for an increasing dose rate. In contrast, when the electrodes are fully covering the whole sample, the applied electric field remains uniformly distributed throughout the entire sample, and the internal $\mathbf{E}_{\mathbf{i}}$ field does thus remain negligible with respect to this applied electric field that extends throughout the sample. As a result, the CCE remains at $100 \%$ due to the I-V curve saturation over a large bias range. In this case, negligible current variation was observed, and the detector response was dose rate independent.

\section{B. Impact of diamond dimensions on small beam $\mathrm{OF}$}

\section{I-V curves}

Figure 7 presents the current measured with SCDDo-C and SCDDo-D under irradiation with respect to the electric field values, thus normalized with respect to the thickness. These measurements were performed in order to select the optimal bias-voltage for OF measurement. These two curves were symmetrical, but the shape was different for both detectors. For SCDDo$\mathrm{D}$, the current reached a saturation value above $0.1 \mathrm{~V} \mu \mathrm{m}^{-1}$, whereas for SCDDo-C the current

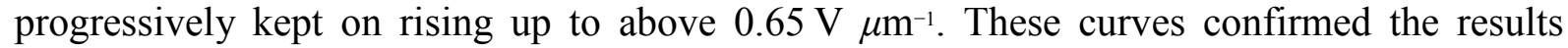
observed previously for detectors SCDDo-A and SCDDo-B. 
FIG. 7.Current versus electric field intensity measured for SCDDo-C and SCDDo-D. This latter dosimeter presents a saturation current due to its electrodes geometry.

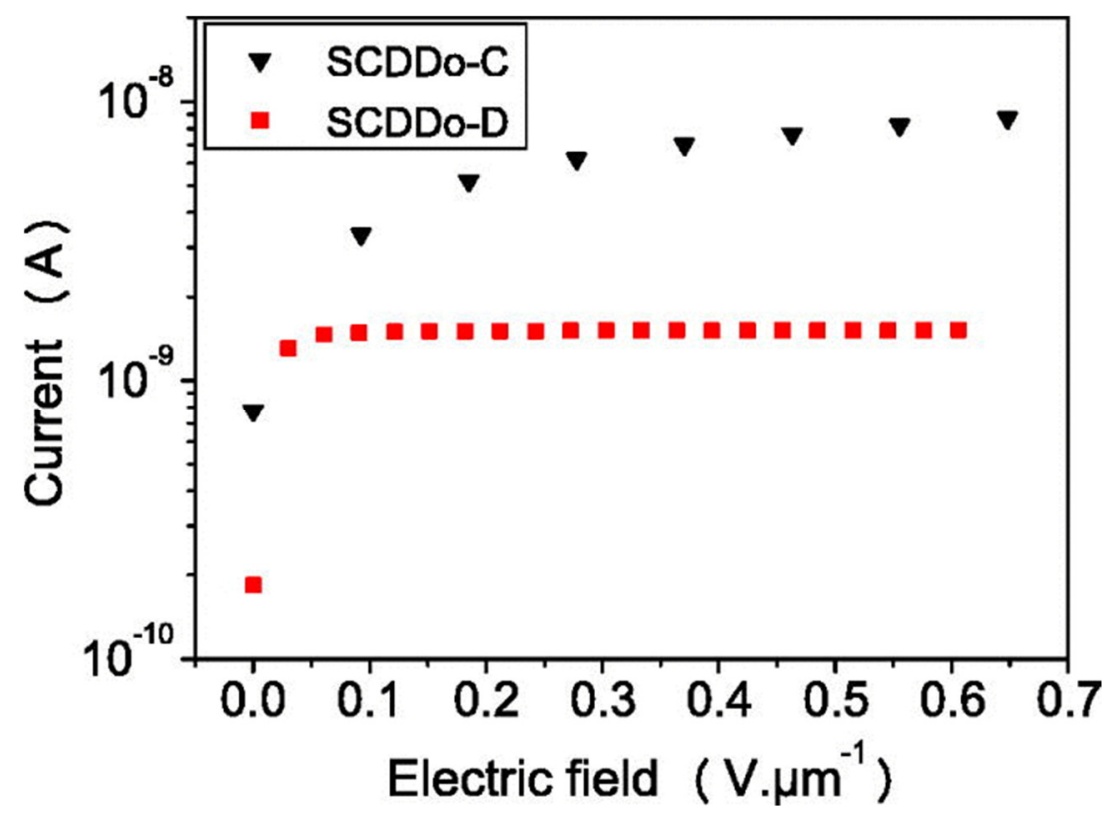

For the following measurements performed in a clinical environment, an electric field of approximately $0.3 \mathrm{~V} \mu \mathrm{m}^{-1}$ was used for polarization of both dosimeters, corresponding to a bias voltage of $+50 \mathrm{~V}$ for SCDDo-D and $+150 \mathrm{~V}$ for SCDDo-C. This electric field value situated in the saturation current region for SCDDo-D ensured a maximum CCE for this detector.

\section{Small beam OF determination}

Figure 8 and Table VI display the OF calculated by MC simulations in the sensitive volume of various diamonds in comparison with OF calculated in a small voxel of water. In this part, the active volume was defined as the volume of diamond situated between electrodes of millimetric dimensions. These results showed that for field sizes above $2 \times 2 \mathrm{~cm}^{2}$, diamond OF was in a good agreement with "reference" water OF (better than $2 \%$ ), for all diamond dimensions, the largest beam of $10 \times 10 \mathrm{~cm}^{2}$ being the reference field. Concerning the smallest field size $\left(0.5 \times 0.5 \mathrm{~cm}^{2}\right)$, diamond OF was in good agreement with "reference" water OF (better than $2 \%$ ) only for the smallest samples presenting lateral dimensions of $1 \times 1 \mathrm{~mm}^{2}$ and a thickness lower than $300 \mu \mathrm{m}$. A maximum difference of $10.9 \%$ was found for the largest diamond dimensions $\left(4 \times 4 \times 0.55 \mathrm{~mm}^{3}\right)$ in this small photon beam. The diamond OF was over-estimated for large samples in small beam where electronic equilibrium was not achieved. This over-estimation was increased with increasing diamond lateral dimensions and thicknesses. 
FIG. 8.Relative difference between OFs in diamond sensitive volume calculated with MC and OFs calculated in a small voxel of water $\left(1 \times 1 \times 0.15 \mathrm{~mm}^{3}\right)$. The sensitive volume was defined as the volume of diamond between small electrodes of millimetric dimensions (square or circular). The small thickness of the diamond chip was facing the beam. OFs were calculated at $5 \mathrm{~cm}$ in a $20 \times 20 \times 20 \mathrm{~cm}^{3}$ water phantom, with an SSD of $100 \mathrm{~cm}$. OFs were normalized to a $10 \times 10 \mathrm{~cm}^{2}$ field.

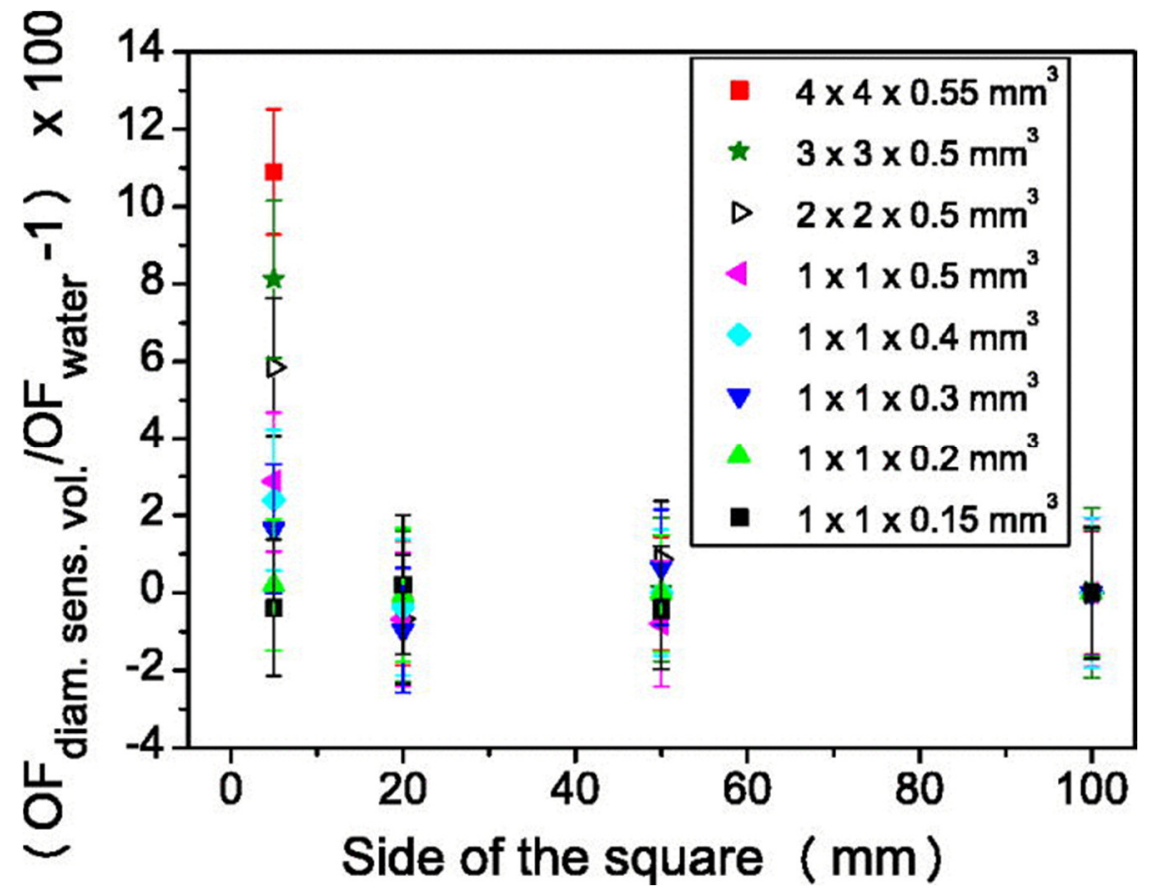

TABLE VI. OF values in diamond sensitive volume calculated with $\mathrm{MC}$ and OF values calculated in a small voxel of water $\left(1 \times 1 \times 0.15 \mathrm{~mm}^{3}\right)$. The sensitive volume was defined as the volume of diamond between small electrodes of millimetric dimensions (square or circular). The small thickness of the diamond chip was facing the beam. OFs were calculated at $5 \mathrm{~cm}$ in a $20 \times 20 \times 20 \mathrm{~cm}^{3}$ water phantom, with an SSD of $100 \mathrm{~cm}$. OFs were normalized to a $10 \times$ $10 \mathrm{~cm}^{2}$ field.

\begin{tabular}{|c|c|c|c|c|}
\hline \multirow{2}{*}{$\begin{array}{l}\text { Diamond } \\
\text { dimensions }\end{array}$} & \multirow{2}{*}{$\begin{array}{l}\text { Electrodes } \\
\text { dimensions }\end{array}$} & \multicolumn{3}{|l|}{$\mathbf{O F}$} \\
\hline & & $\begin{array}{l}0.5 \times 0.5 \mathrm{~cm}^{2} \\
\text { beam }\end{array}$ & $2 \times 2 \mathrm{~cm}^{2}$ beam & $4 \times 4 \mathrm{~cm}^{2}$ beam \\
\hline $4 \times 4 \times 0.55 \mathrm{~mm}^{3}$ & $1 \mathrm{~mm} \varnothing$ & $0.652 \pm 0.006$ & $0.859 \pm 0.008$ & $0.916 \pm 0.008$ \\
\hline $3 \times 3 \times 0.50 \mathrm{~mm}^{3}$ & $1 \mathrm{~mm} \varnothing$ & $0.636 \pm 0.010$ & $0.858 \pm 0.013$ & $0.917 \pm 0.013$ \\
\hline $2 \times 2 \times 0.50 \mathrm{~mm}^{3}$ & $1 \mathrm{~mm} \varnothing$ & $0.623 \pm 0.007$ & $0.856 \pm 0.009$ & $0.924 \pm 0.008$ \\
\hline $1 \times 1 \times 0.50 \mathrm{~mm}^{3}$ & $1 \times 1 \mathrm{~mm}^{2}$ & $0.605 \pm 0.007$ & $0.856 \pm 0.010$ & $0.909 \pm 0.010$ \\
\hline $1 \times 1 \times 0.40 \mathrm{~mm}^{3}$ & $1 \times 1 \mathrm{~mm}^{2}$ & $0.602 \pm 0.007$ & $0.858 \pm 0.010$ & $0.916 \pm 0.010$ \\
\hline $1 \times 1 \times 0.30 \mathrm{~mm}^{3}$ & $1 \times 1 \mathrm{~mm}^{2}$ & $0.598 \pm 0.006$ & $0.853 \pm 0.009$ & $0.922 \pm 0.008$ \\
\hline $1 \times 1 \times 0.20 \mathrm{~mm}^{3}$ & $1 \times 1 \mathrm{~mm}^{2}$ & $0.589 \pm 0.006$ & $0.861 \pm 0.010$ & $0.916 \pm 0.008$ \\
\hline $1 \times 1 \times 0.15 \mathrm{~mm}^{3}$ & $1 \times 1 \mathrm{~mm}^{2}$ & $0.586 \pm 0.007$ & $0.863 \pm 0.011$ & $0.912 \pm 0.010$ \\
\hline \multicolumn{2}{|c|}{ Voxel of water $\left(1 \times 1 \times 0.15 \mathrm{~mm}^{3}\right)$} & $0.588 \pm 0.008$ & $0.861 \pm 0.011$ & $0.916 \pm 0.001$ \\
\hline
\end{tabular}


These results were confirmed experimentally. OF values measured with SCDDo-C and SCDDo-D, in comparison with $\mu \mathrm{LiF}$ and EBT2 films, are reported in Table VII for the CyberKnife and the Clinac 2100. Considering the good agreement (better than 2\%) between OFs measured with $\mu \mathrm{LiF}$ and EBT2 films for these two radiotherapy facilities, Figure 9 shows the relative difference between the OF values measured with the diamond detectors and the mean OFs measured with the two types of passive dosimeters. The error bars in the plot included the measurement uncertainties of the $\mu \mathrm{LiF}(0.8 \%)$, EBT2 films (1.8\%) (Bassinet et al., 2013), and the standard deviation over five measurements performed with each SCDDo. A good agreement between SCDDo-C $\left(4.14 \times 4.13 \times 0.55 \mathrm{~mm}^{3}\right.$ diamond $)$ and the passive dosimeters was observed for field sizes larger than $2 \times 2 \mathrm{~cm}^{2}$. However, large discrepancies were observed for the smallest beam sizes, with a maximum difference of $10.8 \%$ for the $0.5 \mathrm{~cm}$-diameter beam delivered by the CyberKnife system and $9.2 \%$ for the $0.6 \times 0.6 \mathrm{~cm}^{2}$ beam from the Clinac 2100 . In contrast, OFs measured with SCDDo-D (diamond of $1.08 \times 1.06 \times 0.16 \mathrm{~mm}^{3}$ ) were in quite good agreement with the passive dosimeters for all beam sizes, taking into account the dose measurement uncertainties, with a maximum difference of $3.6 \%$ and $4.2 \%$ observed, respectively, for the $0.5 \mathrm{~cm}$-diameter field from the CyberKnife and for the $0.6 \times 0.6 \mathrm{~cm}^{2}$ beam delivered by the Clinac 2100 .

FIG. 9.Relative difference between OFs measured with SCDDo-C $\left(4.14 \times 4.13 \times 0.55 \mathrm{~mm}^{3}\right.$ diamond, $1 \mathrm{~mm}$-diam. electrodes $)$ or SCDDo-D $\left(1.08 \times 1.06 \times 0.16 \mathrm{~mm}^{3}\right.$ diamond, covering electrodes) and mean OFs measured with $\mu \mathrm{LiF}$ and EBT2 films. Measurements were performed on two facilities: the Clinac 2100 equipped with mMLC and the CyberKnife. For the Clinac 2100 , the reference field of OF measurement is $10 \times 10 \mathrm{~cm}^{2}$ beam. For the CyberKnife, the reference field is $6 \mathrm{~cm}$-diameter beam. The small thickness of the diamond chip was facing the beam.

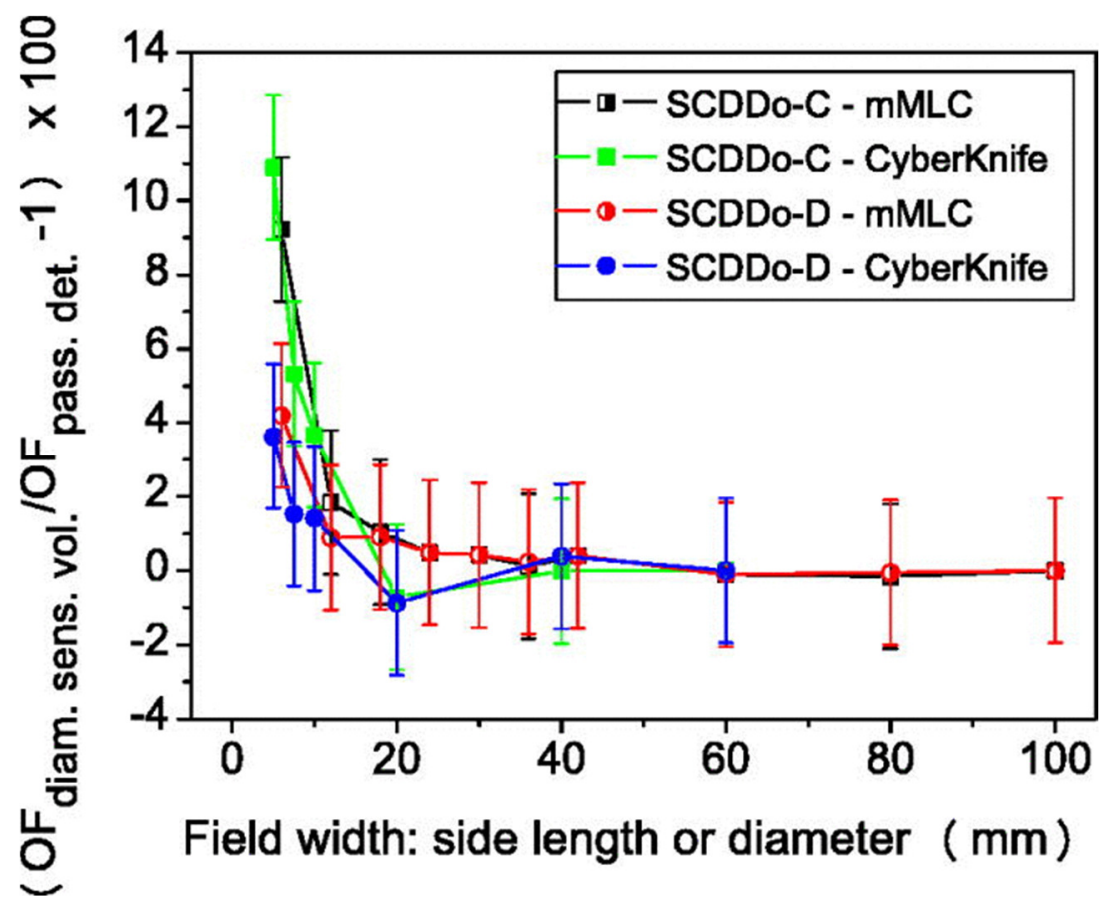


TABLE VII. OF values measured with SCDDo-C, SCDDo-D, $\mu$ LiF, and EBT2 films on two facilities: the Clinac 2100 equipped with mMLC (a) and the CyberKnife system (b). For the Clinac 2100, the reference field of OF measurement is $10 \times 10 \mathrm{~cm}^{2}$ beam. For the CyberKnife, the reference field is $6 \mathrm{~cm}$-diameter beam. The small thickness of the diamond chip was facing the beam.

(a) Clinac 2100

\begin{tabular}{|l|l|l|l|l|}
\hline $\begin{array}{l}\text { Field size } \\
\left(\mathbf{m m}^{2}\right)\end{array}$ & $\begin{array}{l}\text { SCDDo-C } \mathbf{4 . 1 4} \times \\
\mathbf{4 . 1 3} \times \mathbf{0 . 5 5} \mathbf{~ m m}^{3} \\
\text { diamond, } \\
\text { diam. electrodes) }\end{array}$ & $\begin{array}{l}\text { SCDDo-D } \mathbf{~ ( 1 . 0 8 \times ~} \\
\mathbf{1 . 0 6} \times \mathbf{0 . 1 6} \mathbf{~ m m}^{3} \\
\text { diamond, covering } \\
\text { electrodes) }\end{array}$ & $\boldsymbol{\mu L i F}$ & EBT2 \\
\hline $6 \times 6$ & 0.651 & 0.621 & 0.602 & 0.590 \\
\hline $12 \times 12$ & 0.746 & 0.739 & 0.731 & 0.734 \\
\hline $18 \times 18$ & 0.783 & 0.782 & 0.775 & 0.775 \\
\hline $24 \times 24$ & 0.827 & 0.827 & 0.820 & 0.826 \\
\hline $30 \times 30$ & 0.844 & 0.844 & 0.841 & 0.840 \\
\hline $36 \times 36$ & 0.859 & 0.860 & 0.850 & 0.866 \\
\hline $42 \times 42$ & 0.873 & 0.873 & 0.868 & 0.871 \\
\hline $60 \times 60$ & 0.921 & 0.921 & 0.914 & 0.930 \\
\hline $80 \times 80$ & 0.966 & 0.967 & 0.969 & 0.966 \\
\hline
\end{tabular}

(b) CyberKnife

\begin{tabular}{|l|l|l|l|l|}
\hline $\begin{array}{l}\text { Field diameter } \\
(\mathbf{m m})\end{array}$ & $\begin{array}{l}\text { SCDDo-C (4.14 } \times \\
\mathbf{4 . 1 3} \times \mathbf{0 . 5 5} \mathbf{~ m m}^{3} \\
\text { diamond, 1 mm- } \\
\text { diam. electrodes) }\end{array}$ & $\begin{array}{l}\text { SCDDo-D } \mathbf{1 . 0 8} \times \\
\mathbf{1 . 0 6} \times \mathbf{0 . 1 6} \mathbf{~ m m}^{3} \\
\text { diamond, covering } \\
\text { electrodes) }\end{array}$ & $\boldsymbol{\mu L i F}$ & EBT2 \\
\hline 5 & 0.737 & 0.689 & 0.665 & 0.665 \\
\hline 7.5 & 0.863 & 0.832 & 0.815 & 0.824 \\
\hline 10 & 0.901 & 0.881 & 0.863 & 0.875 \\
\hline 20 & 0.968 & 0.966 & 0.967 & 0.983 \\
\hline 40 & 0.989 & 0.993 & 0.979 & 0.999 \\
\hline
\end{tabular}

These results were in good agreement with those presented by Scott et al. (2012) and Fenwick et al. (2013). These latter authors have modified the Spencer-Attix theory in a small nonequilibrium photon radiation field, in order to take into account the impact of detector density (correction factor $P_{p}$ ) and the impact of the changes of electron fluence within the cavity caused by its non-water atomic composition (correction factor $P_{f l}$ ) on dose absorbed in the sensitive volume

$D_{\text {water }}=D_{\text {det }} \cdot P_{p} \cdot P_{f l} \cdot\left[L_{\Delta} / \rho\right]_{\text {det }}^{\text {water }}$ 
where $\left[L_{\Delta} / \rho\right]_{\text {det }}^{\text {water }}$ is the water-to-detector stopping power ratio, $D_{\text {det }}$ is the average dose delivered to the detector sensitive volume, and $D_{\text {water }}$ is the average dose delivered to the same volume of water. In case of a large sensitive volume, the volume averaging effect might also be taken into account to determine $\mathrm{D}_{\text {water }}$ at a point. Fenwick et al. (2013) have shown that $P_{p}$ and $P_{f l}$ factors, evaluated by MC simulations, lie close to unity for field sizes ranging from $2 \times 2 \mathrm{~cm}^{2}$ to $10 \times 10 \mathrm{~cm}^{2}$, meaning that $D_{\text {water }} / D_{\text {det }}$ is mostly equal to $\left[L_{\Delta} / \rho\right]_{\text {det }}^{\text {water }}$, as described by the Spencer-Attix cavity theory. For beam size smaller than $2 \times 2 \mathrm{~cm}^{2}, P_{f l}$ lies close to one for diamond material, whereas $P_{p}$ can reach 0.9 in a $0.5 \times 0.5 \mathrm{~cm}^{2}$ beam for the diamond geometry studied in their work $(0.26 \mathrm{~mm}$-thick cylinder with a diameter of $2.3 \mathrm{~mm})$.

The present study confirmed that the density dependence can be minimized by reducing the volume of non-unit density diamond around the sensitive volume as well as reducing the sensitive volume. In such cases of reduced dimensions, the conditions of the Spencer-Attix theory would be fulfilled and the approximation made in dosimetry protocols (IAEA TRS-398), which consists to not take into account the ratio $\left[L_{\Delta} / \rho\right]_{\text {det }}^{\text {water }}$, could be applied to diamond detector without requiring corrections, since $\left[L_{\Delta} / \rho\right]_{\text {det }}^{\text {water }}$ is almost constant with respect to field sizes (Fenwick et al., 2013). Bouchard et al. (2015a; 2015b) have recently completed the formalism described in Equation (2) by adding the extracameral perturbation factor, concerning the components which are not being part of the sensitive volume. This perturbation factor could explain the remaining differences $(\sim 4 \%)$ between the OF measured with SCDDo-D and the mean value obtained with the passive dosimeters for the smallest beams, despite the reduced diamond dimensions. The selection of the near water-equivalent encapsulating materials was performed in a small photon beam of $2 \times 2 \mathrm{~cm}^{2}$ in a previous study (Marsolat et al., 2013a) but the potential impact of these materials on diamond detector response has not been explored in smaller beam sizes such as those used in this new study.

The impact of sensitive materials with density higher than unity has also been shown for $\mathrm{LiF}$ dosimeters $\left(\rho_{L i F}=2.635\right)$ in small beam dosimetry by Bouchard et al. $(2015 \mathrm{a} ; 2015 \mathrm{~b})$. However, Moignier et al. (2014) have shown the compensation between the mass density effect and the volume averaging effect for $\mathrm{LiF}$ microcubes to be identical to those used in this study, leading to a good agreement (better than 2\%) with the EBT2 radiochromic films for circular field sizes down to $0.5 \mathrm{~cm}$-diameter.

\section{DLC-electrodes}

\section{I-V curves and dose rate dependence}

The impact of the electrode geometry on I-V curve and hence on dose rate response dependence was verified for SCDDo-E presenting a diamond of $1.08 \times 1.06 \times 0.16 \mathrm{~mm}^{3}$ and DLC-electrodes covering the whole diamond surface. I-V characteristic is displayed in Figure 10 and shows that a saturation value of the current was reached at a bias voltage of approximately $20 \mathrm{~V}$. 
FIG. 10.Saturated I-V characteristic measured for SCDDo-E, with DLC electrodes covering the whole diamond surface.

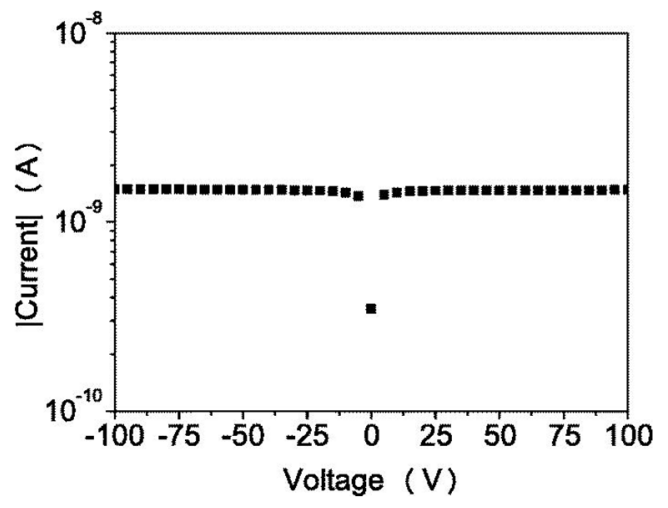

A bias voltage of $+50 \mathrm{~V}$ was then applied to this detector, and the dose rate dependence measurements were performed on the Novalis accelerator. Results are shown in Figure 11. A maximum deviation of $0.5 \%$ of the measured charge with respect to the one measured at 800 MU $\min ^{-1}$ was observed in the investigated dose rate range. This result confirmed the low dose rate dependence of SCDDo response for diamond with electrodes covering the whole surface of the sample, for aluminum as well as for DLC contacts. This study highlighted the importance of considering more the electrode geometry than the electrode material to obtain ideal electrical contacts.

FIG. 11.Dose rate dependence of SCDDo-E response in a $10 \times 10 \mathrm{~cm}^{2}$ field produced by the Novalis system. Percent deviation of the charge measured with SCDDo-E for different dose

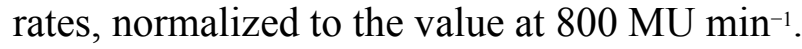

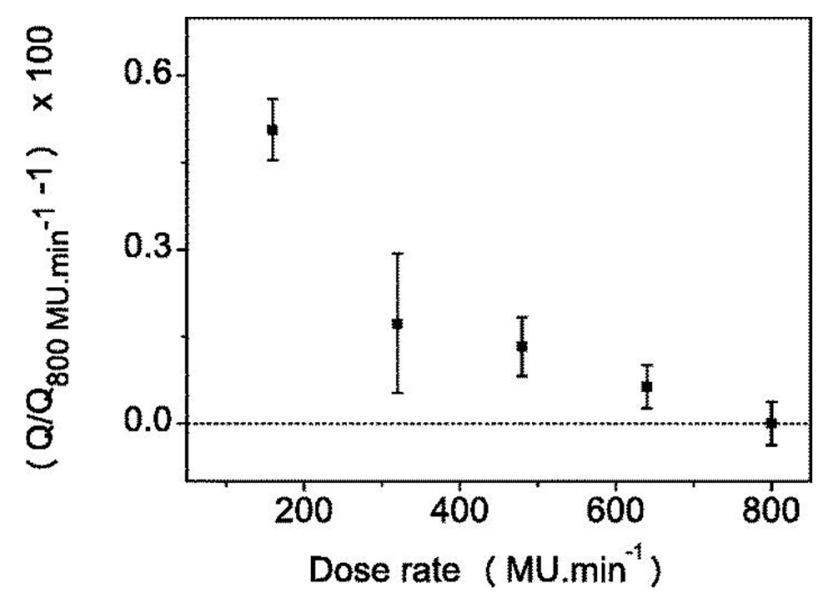

\section{Small beam OF measurements}

OF measurements were performed on the Novalis accelerator using SCDDo-E in comparison with various commercially available detectors. Two different bias voltages applied to SCDDoE were tested, namely, $+50 \mathrm{~V}$ and $+80 \mathrm{~V}$, both giving the same sensitivity as shown previously from the I-V characteristic (Figure 10).

Table VIII reports the values for the OF normalized at the $4.2 \times 4.2 \mathrm{~cm}^{2}$ field, measured with SCDDo-E, the PinPoint chamber, the shielded Sun Nuclear EDGE diode, the unshielded PTW 60017 diode, the $\mu \mathrm{LiF}$, and the EBT2 films. The same values are displayed in Figure 12(a). Considering again the good agreement between the passive dosimeters (better than $2 \%$ ), the deviation of the OF measured with active detectors with respect to the mean value measured with $\mu \mathrm{LiF}$ and EBT2 films is shown in Figure 12(b). These results confirmed the increase of interdetector variations with decreasing field size, and these variations were considerable below 
$1.8 \times 1.8 \mathrm{~cm}^{2}$. A maximum difference of $14.5 \%$ between the OF measured with the EDGE diode and that obtained with the PinPoint chamber was observed for the smallest beam of $0.6 \times 0.6 \mathrm{~cm}^{2}$.

FIG. 12.(a) OFs measured with SCDDo-E at two different bias voltages $(+50 \mathrm{~V}$ and $+80 \mathrm{~V})$ and with various commercially available active and passive detectors on the Novalis system. (b) Relative difference between OFs measured with active dosimeters and mean OF values obtained with $\mu \mathrm{LiF}$ and EBT2 films. OFs were normalized to a $4.2 \times 4.2 \mathrm{~cm}^{2}$ field.

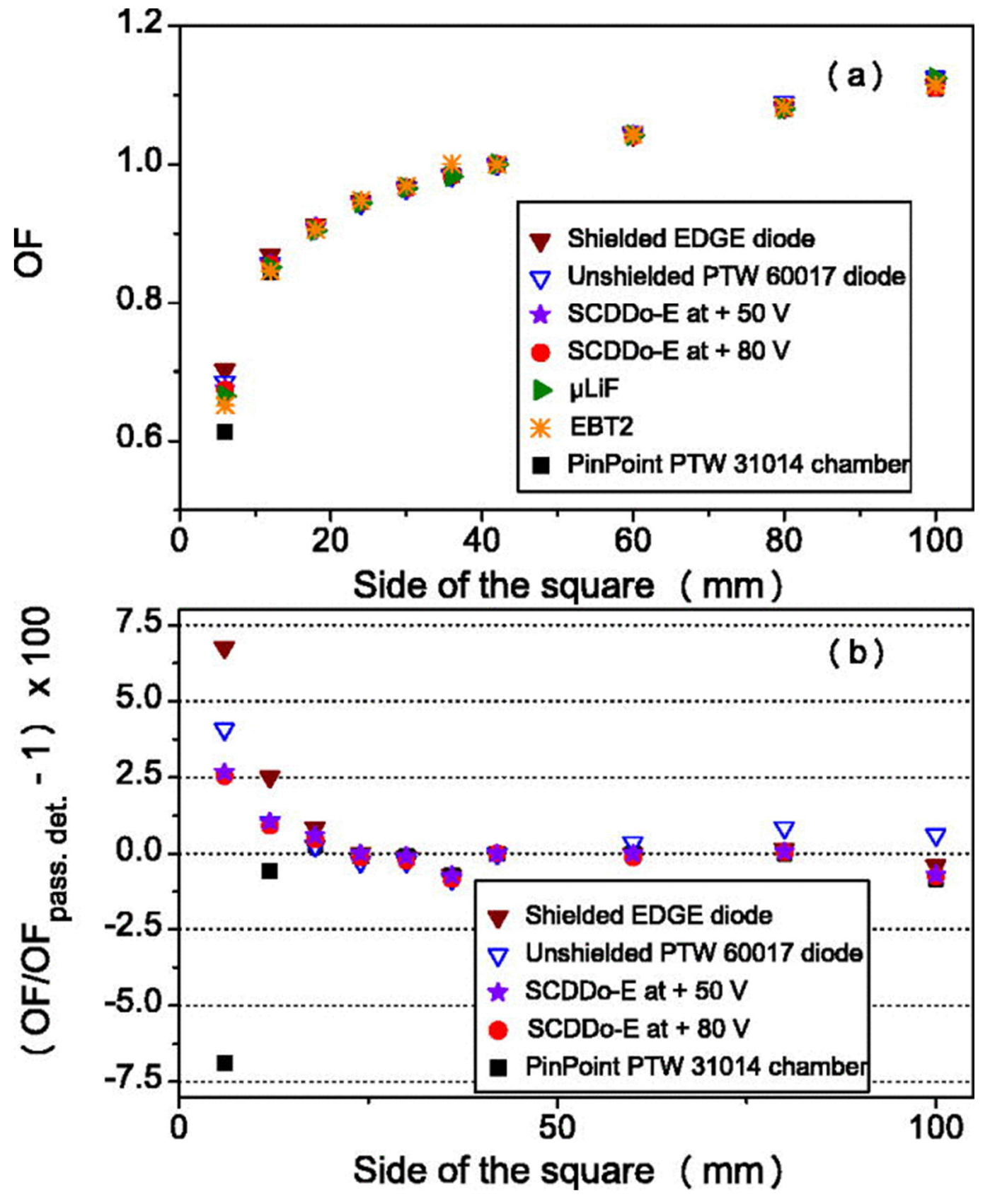


TABLE VIII. OF values measured with SCDDo-E and various commercially available detectors on the Novalis system. OFs were normalized to a $4.2 \times 4.2 \mathrm{~cm}^{2}$ field. Uncertainties (1SD) were indicated for each detector.

\begin{tabular}{|c|c|c|c|c|c|c|c|}
\hline $\begin{array}{l}\text { Field } \\
\text { size } \\
\left(\mathbf{m m}^{2}\right)\end{array}$ & $\begin{array}{l}\text { SCDDo- } \\
\mathbf{E}+50 \mathrm{~V} \\
( \pm 0.1 \%)\end{array}$ & $\begin{array}{l}\text { SCDDo- } \\
\mathbf{E}+\mathbf{8 0} \mathrm{V} \\
( \pm \mathbf{0 . 1 \%})\end{array}$ & $\begin{array}{l}\mu \mathrm{LiF} \\
( \pm \mathbf{0 . 8 \%})\end{array}$ & $\begin{array}{l}\text { EBT2 } \\
( \pm 1.8 \%)\end{array}$ & $\begin{array}{l}\text { Shielded } \\
\text { EDGE } \\
\text { diode } \\
( \pm 0.3 \%)\end{array}$ & $\begin{array}{l}\text { Unshielded } \\
\text { PTW } \\
\text { 60017 } \\
\text { diode } \\
( \pm 0.2 \%)\end{array}$ & $\begin{array}{l}\text { PinPoint } \\
\text { PTW } \\
31014 \\
\text { chamber } \\
( \pm 0.1 \%)\end{array}$ \\
\hline $6 \times 6$ & 0.675 & 0.675 & 0.664 & 0.651 & 0.702 & 0.685 & 0.613 \\
\hline $12 \times 12$ & 0.857 & 0.856 & 0.851 & 0.846 & 0.870 & 0.857 & 0.844 \\
\hline $18 \times 18$ & 0.911 & 0.910 & 0.905 & 0.906 & 0.913 & 0.908 & 0.908 \\
\hline $24 \times 24$ & 0.946 & 0.945 & 0.944 & 0.948 & 0.946 & 0.944 & 0.946 \\
\hline $30 \times 30$ & 0.967 & 0.965 & 0.966 & 0.970 & 0.967 & 0.965 & 0.967 \\
\hline $36 \times 36$ & 0.984 & 0.983 & 0.983 & 1.001 & 0.984 & 0.983 & 0.984 \\
\hline $42 \times 42$ & 1.000 & 1.000 & 1.000 & 1.000 & 1.000 & 1.000 & 1.000 \\
\hline $60 \times 60$ & 1.042 & 1.041 & 1.042 & 1.043 & 1.042 & 1.046 & 1.042 \\
\hline $80 \times 80$ & 1.082 & 1.081 & 1.080 & 1.082 & 1.083 & 1.090 & 1.081 \\
\hline $\begin{array}{l}100 \times \\
100\end{array}$ & 1.112 & 1.111 & 1.124 & 1.114 & 1.115 & 1.126 & 1.110 \\
\hline
\end{tabular}

For the smallest beam sizes (less than $1.8 \times 1.8 \mathrm{~cm}^{2}$ ), the OF values measured with the PinPoint detector were under-estimated compared with the mean values obtained with the passive dosimeters, with a maximum difference of $-6.8 \%$ for $0.6 \times 0.6 \mathrm{~cm}^{2}$ beam. This under-estimation was explained by the volume averaging effect and by the presence of the air cavity which decreases the electron fluence (Moignier et al., 2014). But for field sizes larger than $1.8 \times 1.8 \mathrm{~cm}^{2}$, the PinPoint chamber and the passive dosimeters were in good agreement (better than $1 \%)$.

OFs measured with silicon diodes were over-estimated in small beams, mainly due to the density of silicon which is greater than unity $\left(\rho_{\text {silicon }}=2.33\right)$ (Underwood et al., 2013; Moignier et al., 2014; and Bouchard et al., 2015a; 2015b). The density of the silicon diodes components other than the sensitive volume can also influence the detector response as explained by the same authors. This so-called extracameral perturbation factor might be taken into account in small beam dosimetry, in addition to the volume averaging effect, the density, and the atomic composition perturbation factors, as recently shown by Bouchard et al. (2015a; 2015b). As shown in Table VIII, the over-estimation of the OFs in small beams was more important for the EDGE diode than for the PTW 60017 diode, with a maximum difference of $6.7 \%$ and $4.1 \%$, respectively, in comparison with the mean OF of the passive dosimeters. This difference of behavior between both diodes was due to their different design. For the EDGE diode, a metallic shielding allows to selectively absorb the low energy photons, which would otherwise lead to an over-response of the diode due to the photoelectric effect in high-Z silicon (Griessbach et al., 2005; Eklund and Ahnesjö, 2010; Pantelis et al., 2010; Cranmer-Sargison et al., 2011; Bassinet et al., 2013; and Moignier et al. 2014). However, this metallic shielding induces an increase of electron scattering into the active volume, which reduces the lateral electronic disequilibrium in small beam and leads to an over-response of the EDGE diode in small beam 
compared with the unshielded diodes (Pantelis et al., 2010; Pantelis et al., 2012; Francescon et al., 2012; and Bassinet et al., 2013).

The standard deviation of OFs measured with SCDDo-E was \pm 0.001 for each beam size, due to the good stability and reproducibility of the device. No significant difference was found between OFs measured with SCDDo-E at $+50 \mathrm{~V}$ and $+80 \mathrm{~V}$. This result indicated the possibility of using our diamond detector at different voltages for which the detector sensitivity remains constant.

For beam size larger than $1.8 \times 1.8 \mathrm{~cm}^{2}$, SCDDo-E and PinPoint ionization chamber were in good agreement, with a deviation below 0.2\%. Furthermore, SCDDo-E and the passive dosimeters were in good agreement for all beam sizes (better than 1.1\%) except for the smallest beam of $0.6 \times 0.6 \mathrm{~cm}^{2}$ with a deviation of $2.6 \%$. This over-estimation of OF values in small beam was nevertheless reduced in comparison with SCDDo-D presenting the same diamond geometry but aluminum electrodes. This difference in small beams between SCDDo-D and SCDDo-E, relatively to the passive dosimeters, could be explained by the large uncertainties in OF measurements with the passive dosimeters or by the use of lower-Z electrodes material. The results presented in Figure 12 and Table VIII indicated also the better performance of this allcarbon detector than the commercially available active dosimeters.

\section{CONCLUSION}

To our knowledge, this is the first study demonstrating the positive impact of reducing diamond sample dimensions on the small beam OF measurements for a high-resolution diamond detector (millimetric electrodes), using both experimental and simulations methods. The high density of diamond (3.51 times greater than that of water) causes an over-estimation of the small beam OF for diamond dimensions larger than approximately $1 \times 1 \times 0.3 \mathrm{~mm}^{3}$ as shown by $\mathrm{MC}$ simulations. Experimentally, this over-estimation goes up to $10.8 \%$ in $0.5 \mathrm{~cm}$-diameter beam produced by the CyberKnife system for diamond of $4.14 \times 4.13 \times 0.55 \mathrm{~mm}^{3}$ with $1 \mathrm{~mm}$ diameter electrodes, in comparison with the mean value obtained with passive dosimeters. This work has shown that reducing thickness and lateral dimensions was relevant to accurately measure small beam OFs.

The diamond dosimeter recently commercialized by PTW-Freiburg (type 60019) has an active volume with a very small thickness of $1 \mu \mathrm{m}$, but the large lateral dimensions of $2.2 \mathrm{~mm}$ necessary to keep a high signal to noise ratio requires volume averaging effect correction factors for small beam OF measurements. However, according to the present study and previously published work (Ralston et al., 2014 and Underwood et al., 2015), the volume averaging effect correction is not sufficient for PTW 60019 diamond detector, as the high-density effect remains predominant under small beams and leads to an over-estimation of the OF values measured in small beams. This over-response of the PTW 60019 diamond detector in small beam might be due to the presence of $400 \mu \mathrm{m}$ thick diamond substrate underneath the device's sensitive volume. Indeed, this new study has shown that the amount of diamond around the active volume strongly affects the over-response of the diamond detector.

This study is also the first one showing the impact of electrode size on the dose rate dependence of diamond dosimeters. Two different electrode geometries studied in this work have highlighted that in diamonds with low defect concentrations, devices are dose-rate independent when the electrodes are covering the entire diamond surface. Our study was conducted on electronic grade Element Six samples, and CCE were, in this condition, systematically reaching $100 \%$ beyond an applied threshold voltage.

The impact of diamond dimensions and electrode geometry was verified with DLC contacts. This optimization work has led to a diamond detector of approximately $1 \times 1 \times 0.15 \mathrm{~mm}^{3}$ with 
DLC electrodes covering the whole surface. Low dose-rate dependence of this detector was observed, with a variation of $0.5 \%$ over a wide range of dose rates available on the Novalis system. The over-response of this diamond detector in small beam was reduced in comparison with diamond with larger dimensions and aluminum contacts. This over-response was estimated to be $2.6 \%$ relatively to the passive dosimeters for the smallest beam of $0.6 \times 0.6 \mathrm{~cm}^{2}$. However, this relative difference was lower than that observed with other active detectors, namely, a PinPoint ionization chamber, shielded and unshielded diodes. This new study has demonstrated the potentiality of such a high-performance all-carbon detector in small photon beam dosimetry.

\section{ACKNOWLEDGMENTS}

This work was performed in the framework of the "DIADOMI" project which was granted by the French National Research Agency.

\section{REFERENCES}

1. Almaviva, S., Cancaglioni, I., Consorti, R., De Notaristefani, F., Manfredotti, C., Marinelli, M., Milani, E., Petrucci, A., Prestopino, G., Verona, C., and Verona-Rinati, G., " Synthetic single crystal diamond dosimeters for intensity modulated radiation therapy applications,"

Nucl. Instrum. Methods Phys. Res., Sect. A 608, 191-194 (2009). https://doi.org/10.1016/i.nima.2009.07.004.

2. Bassinet, C., Huet, C., Derreumaux, S., Brunet, G., Chea, M., Baumann, M., Lacornerie, T., Gaudaire-Josset, S., Trompier, F., Roch, P., Boisserie, G., and Clairand, I., " Small fields output factors measurements and correction factors determination for several detectors for a CyberKnife and linear accelerators equipped with microMLC and circular cones," Med. Phys. 40, 071725 (2013). https://doi.org/10.1118/1.4811139.

3. Bassinet, C., Robbes, I., Barbier, L., Baumann, M., Kernisant, B., and Trompier, F., “ Characterization of 7LiF:Mg,Ti TLD micro-cubes," Radiat. Meas. 45, 646-648 (2010). https://doi.org/10.1016/j.radmeas.2009.12.005.

4. Bergonzo, P., Tromson, D., Descamps, C., Hamrita, H., Mer, C., Tranchant, N., and Nesladek, M., " Improving diamond detectors: A device case," Diamond Relat. Mater. 16, 1038-1043 (2007). https://doi.org/10.1016/j.diamond.2006.11.099.

5. Betzel, G. T., Lansley, S. P., Baluti, F., Reinisch, L., and Meyer, J., " Clinical investigations of a CVD diamond detector for radiotherapy dosimetry," Phys. Med. 28, 144-152 (2012). https://doi.org/10.1016/j.ejmp.2011.04.003.

6. Bouchard, H., Seuntjens, J., Duane, S., Kamio, Y., and Palmans, H., “ Detector response in megavoltage small photon beams. I. Theoretical concepts,” Med. Phys. 42, 6033-6047 (2015a). https://doi.org/10.1118/1.4930053.

7. Bouchard, H., Kamio, Y., Palmans, H., Seuntjens, J., and Duane, S., “ Detector dose response in megavoltage small photon beams. II. Pencil beam perturbation effects," Med. Phys. 42, 6048-6061 (2015b). https://doi.org/10.1118/1.4930798.

8. BrainLAB Physics, Technical Reference Guide Rev 1.0, 2008.

9. Ciancaglioni, I., Marinelli, M., Milani, E., Prestopino, G., Verona, C., Verona-Rinati, G., Consorti, R., Petrucci, A., and De Notaristefani, F., " Dosimetric characterization of a synthetic single crystal diamond detector in clinical radiation therapy small photon beams," Med. Phys. 39, 4493-4501 (2012). https://doi.org/10.1118/1.4729739. 
10. Cranmer-Sargison, G., Weston, S., Evans, J. A., Sidhu, N. P., and Thwaites, D. I., “ Implementing a newly proposed Monte Carlo based small field dosimetry formalism for a comprehensive set of diode detectors," Med. Phys. 38, 6592-6602 (2011). https://doi.org/10.1118/1.3658572.

11. Das, I. J., Ding, G. X., and Ahnesjö, A., " Small fields: Nonequilibrium radiation dosimetry," Med. Phys. 35, 206-215 (2008). https://doi.org/10.1118/1.2815356.

12. De Angelis, C., Onori, S., Pacilio, M., Cirrone, G. A. P., Cuttone, G., Raffaele, L., Bucciolini, M., and Mazzocchi, S., "An investigation of the operating characteristics of two PTW diamond detectors in photon and electron beams," Med. Phys. 29, 248-254 (2002). https://doi.org/10.1118/1.1446101.

13. Dzierma, Y., Licht, N., Nuesken, F., and Ruebe, C., " Beam properties and stability of a flattening-filter free 7 MV beam-An overview," Med. Phys. 39, 2595-2602 (2012). https://doi.org/10.1118/1.3703835.

14. Eklund, K. and Ahnesjö, A., " Spectral perturbations from silicon diode detector encapsulation and shielding in photon fields," Med. Phys. 37, 6055-6060 (2010). https://doi.org/10.1118/1.3501316.

15. Fenwick, J. D., Kumar, S., Scott, A. J., and Nahum, A. E., "Using cavity theory to describe the dependence on detector density of dosimeter response in non-equilibrium small fields," Phys. Med. Biol. 58, 2901-2923 (2013). https://doi.org/10.1088/0031-9155/58/9/2901.

16. Fidanzio, A., Azario, L., Miceli, R., Russo, A., and Piermattei, A., "PTW-diamond detector: dose rate and particle type dependence," Med. Phys. 27, 2589-2593 (2000). https://doi.org/10.1118/1.1318218.

17. Fowler, J. F., Radiation Dosimetry, edited by Attix, F. H. and Roesch, W. C. ( Academic Press, New York, 1966).

18. Francescon, P., Kilby, W., Satariano, N., and Cora, S., “ Monte Carlo simulated correction factors for machine specific reference field dose calibration and output factor measurement using fixed and iris collimators on the CyberKnife system," Phys. Med. Biol. 57, 3741-3758 (2012). https://doi.org/10.1088/0031-9155/57/12/3741.

19. Gagnon, J. C., Thériault, D., Guillot, M., Archambault, L., Beddar, S., Gingras, L., and Beaulieu, L., " Dosimetric performance and array assessment of plastic scintillation detectors for stereotactic radiosurgery quality assurance," Med. Phys. 39, 429-436 (2012). https://doi.org/10.1118/1.3666765.

20. Garino, Y., Lo Giudice, A., Manfredotti, C., Marinelli, M., Milani, E., Tucciarone, A., and Verona-Rinati., G., " Performances of homoepitaxial single crystal diamond in diagnostic xray dosimetry,” Appl. Phys. Lett. 88, 151901 (2006). https://doi.org/10.1063/1.2195025.

21. Górka, G., Nilsson, B., Fernández-Varea, J. M., Svensson, R., and Brahme, A., “ Influence of electrodes on the photon energy deposition in CVD-diamond dosimeters studied with the Monte Carlo code PENELOPE," Phys. Med. Biol. 51, 3607-3623 (2006). https://doi.org/10.1088/0031-9155/51/15/001.

22. Griessbach, I., Lapp, M., Bohsung, J., Gademann, G., and Harder, D., " Dosimetric characteristics of a new unshielded silicon diode and its application in clinical photon and electron beams," Med. Phys. 32, 3750-3754 (2005). https://doi.org/10.1118/1.2124547.

23. Hoban, P. W., Heydarian, M., Beckham, W. A., and Beddoe, A. H., " Dose rate dependence of a PTW diamond detector in the dosimetry of a 6 MV photon beam," Phys. Med. Biol. 39, 1219-1229 (1994). https://doi.org/10.1088/0031-9155/39/8/003. 
24. Huet, C., Dagois, S., Derreumaux, S., Trompier, F., Chenaf, C., and Robbes, I., “ Characterization and optimization of EBT2 radiochromic films dosimetry system for precise measurements of output factors in small fields used in radiotherapy," Radiat. Meas. 47, 40-49 (2012). https://doi.org/10.1016/j.radmeas.2011.10.020.

25. Lárraga-Gutiérrez, J. M., Ballesteros-Zebadúa, P., Rodríguez-Ponce, M., García-Garduño, O. A., and de la Cruz, O. O., " Properties of a commercial PTW-60019 synthetic diamond detector for the dosimetry of small radiotherapy beams," Phys. Med. Biol. 60, 905-924 (2015). https://doi.org/10.1088/0031-9155/60/2/905.

26. Laub, W. U. and Crilly, R., " Clinical radiation therapy measurements with a new commercial synthetic single crystal diamond detector," J. Appl. Clin. Med. Phys. 15, 4890 (2014). https://doi.org/10.1120/jacmp.v15i6.4890.

27. Laub, W. U. and Wong, T., " The volume effect of detectors in the dosimetry of small fields used in IMRT,” Med. Phys. 30, 341-347 (2003). https://doi.org/10.1118/1.1544678.

28. Marsolat, F., Tromson, D., Tranchant, N., Pomorski, M., Lazaro-Ponthus, D., Bassinet, C., Huet, C., Derreumaux, S., Chea, M., Boisserie, G., Alvarez, J., and Bergonzo, P., " Diamond dosimeter for small beam stereotactic radiotherapy," Diamond Relat. Mater. 33, 63-70 (2013a). https://doi.org/10.1016/j.diamond.2013.01.003.

29. Marsolat, F., Tromson, D., Tranchant, N., Pomorski, M., Le Roy, M., Donois, M., Moignau, F., Ostrowsky, A., De Carlan, L., Bassinet, C., Huet, C., Derreumaux, S., Chea, M., Cristina, K., Boisserie, G., and Bergonzo, P., " A new single crystal diamond dosimeter for small beam: comparison with different commercial active detectors," Phys. Med. Biol. 58, 7647-7660 (2013b). https://doi.org/10.1088/0031-9155/58/21/7647.

30. Martens, C., De Wagter, C., and De Neve, W., " The value of the PinPoint ion chamber for characterization of small field segments used in intensity-modulated radiotherapy," Phys. Med. Biol. 45, 2519-2530 (2000). https://doi.org/10.1088/0031-9155/45/9/306.

31. Mazurier, J., Salvat, F., Chauvenet, B., and Barthe, J., " Simulation of photon beams from a Saturne 43 accelerator using the code PENELOPE," Phys. Med. 15, 101-110 (1999).

32. Moignier, C., Huet, C., and Makovicka, L., " Determination of the $\mathrm{k}((\mathrm{fclin}, \mathrm{fmsr})(\mathrm{Qclin}, \mathrm{Qmsr}))$ correction factors for detectors used with an $800 \mathrm{MU} / \mathrm{min}$ CyberKnife system equipped with fixed collimators and a study of detector response to small photon beams using a Monte Carlo method," Med. Phys. 41, 071702 (2014). https://doi.org/10.1118/1.4881098.

33. Morales, J. E., Crowe, S. B., Hill, R., Freeman, N., and Trapp, J. V., “ Dosimetry of conedefined stereotactic radiosurgery fields with commercial synthetic diamond detector," Med. Phys. 41, 111702 (2014). https://doi.org/10.1118/1.4895827.

34. Pantelis, E., Moutsatsos, A., Zourari, K., Kilby, W., Antypas, C., Papagiannis, P., Karaiskos, P., Georgiou, E., and Sakelliou, L., " On the implementation of a recently proposed dosimetric formalism to a robotic radiosurgery system," Med. Phys. 37, 2369-2379 (2010). https://doi.org/10.1118/1.3404289.

35. Pantelis, E., Moutsatsos, A., Zourari, K., Petrokokkinos, L., Sakelliou, L., Kilby, W., Antypas, C., Papagiannis, P., Karaiskos, P., Georgiou, E., and Seimenis, I., " On the output factor measurements of the CyberKnife iris collimator small fields: Experimental determination of the kfclin,fmsrQclin,QmsrkQclin,Qmsrfclin,fmsr correction factors for microchamber and diode detectors," Med. Phys. 39, 4875-4885 (2012). https://doi.org/10.1118/1.4736810. 
36. Ralston, A., Liu, P., Warrener, K., McKenzie, D., and Suchowerska, N., " Small field diode correction factors derived using an air core fibre optic scintillation dosimeter and EBT2 film," Phys. Med. Biol. 57, 2587-2602 (2012). https://doi.org/10.1088/0031-9155/57/9/2587.

37. Ralston, A., Tyler, M., Liu, P., McKenzie, D., and Suchowerska, N., " Over-response of synthetic microdiamond detectors in small radiation fields," Phys. Med. Biol. 59, 5873-5881 (2014). https://doi.org/10.1088/0031-9155/59/19/5873.

38. Salvat, F., Fernandez-Varea, J. M., and Sempau, J., PENELOPE-2006: A code System for Monte Carlo Simulation of Electron and Photon Transport ( OECD Nuclear Energy Agency, 2006).

39. Scherf, C., Peter, C., Moog, J., Licher, J., Kara, E., Zink, K., Rödel, C., and Ramm, U., “ Silicon diodes as an alternative to diamond detectors for depth dose curves and profile measurements of photon and electron radiation," Strahlenther Onkol. 185, 530-536 (2009). https://doi.org/10.1007/s00066-009-2004-X.

40. Schirru, F., Kisielewicz, K., Nowak, T., and Marczewska, B., " Single crystal diamond detector for radiotherapy," J. Phys. D: Appl. Phys. 43, 265101 (2010). https://doi.org/10.1088/0022-3727/43/26/265101.

41. Scott, A. J. D., Kumar, S., Nahum, A. E., and Fenwick, J. D., "Characterizing the influence of detector density on dosimeter response in non-equilibrium small photon fields," Phys. Med. Biol. 57, 4461-4476 (2012). https://doi.org/10.1088/0031-9155/57/14/4461.

42. Scott, A. J. D., Nahum, A. E., and Fenwick, J. D., "Using a Monte Carlo model to predict dosimetric properties of small radiotherapy photon fields," Med. Phys. 35, 4671-4684 (2008). https://doi.org/10.1118/1.2975223.

43. Spadaro, S., Conte, A., Pimpinella, M., and Guerra, A. S., " Electrical and dosimetric characterization of a CVD diamond detector with high sensitivity," Radiat. Meas. 48, 1-6 (2013). https://doi.org/10.1016/j.radmeas.2012.11.017.

44. Tranchant, N., Tromson, D., Descamps, C., Isambert, A., Hamrita, H., Bergonzo, P., and Nesladek, M., " High mobility single crystal diamond detectors for dosimetry: Application to radiotherapy," Diamond Relat. Mater. 17, 1297-1301 (2008). https://doi.org/10.1016/j.diamond.2008.03.025.

45. Tromson, D., Rebisz-Pomorska, M., Tranchant, N., Isambert, A., Moignau, F., Moussier, A., Marczewska, B., and Bergonzo, P., " Single crystal CVD diamond detector for high resolution dose measurement for IMRT and novel radiation therapy needs," Diamond Relat. Mater. 19, 1012-1016 (2010). https://doi.org/10.1016/j.diamond.2010.03.008.

46. Underwood, T. S. A., Rowland, B. C., Ferrand, R., and Vieillevigne, L., “Application of the Exradin W1 scintillator to determine Ediode 60017 and microDiamond 60019 correction factors for relative dosimetry within small MV and FFF fields," Phys. Med. Biol. 60, 66696683 (2015).

47. Underwood, T. S., Winter, H. C., Hill, M. A., and Fenwick, J. D., “ Detector density and small field dosimetry: Integral versus point dose measurement schemes," Med. Phys. 40, 082102 (2013). https://doi.org/10.1118/1.4812687. 